Review

\title{
Regulation Systems of Bacteria such as Escherichia coli in Response to Nutrient Limitation and Environmental Stresses
}

\section{Kazuyuki Shimizu ${ }^{1,2}$}

1 Kyushu Institute of Technology, Fukuoka, Iizuka 820-8502, Japan;

E-Mail: shimi@bio.kyutech.ac.jp; Tel.: +81-090-9729-9673; Fax: +81-948-29-7801

2 Institute of Advanced Bioscience, Keio University, Yamagata, Tsuruoka 997-0017, Japan

Received: 9 September 2013; in revised form: 18 November 2013 / Accepted: 6 December 2013 / Published: 30 December 2013

\begin{abstract}
An overview was made to understand the regulation system of a bacterial cell such as Escherichia coli in response to nutrient limitation such as carbon, nitrogen, phosphate, sulfur, ion sources, and environmental stresses such as oxidative stress, acid shock, heat shock, and solvent stresses. It is quite important to understand how the cell detects environmental signals, integrate such information, and how the cell system is regulated. As for catabolite regulation, F1,6B P (FDP), PEP, and PYR play important roles in enzyme level regulation together with transcriptional regulation by such transcription factors as Cra, Fis, CsrA, and cAMP-Crp. $\alpha \mathrm{KG}$ plays an important role in the coordinated control between carbon (C)- and nitrogen $(\mathrm{N})$-limitations, where $\alpha \mathrm{KG}$ inhibits enzyme I (EI) of phosphotransferase system (PTS), thus regulating the glucose uptake rate in accordance with $\mathrm{N}$ level. As such, multiple regulation systems are co-ordinated for the cell synthesis and energy generation against nutrient limitations and environmental stresses. As for oxidative stress, the TCA cycle both generates and scavenges the reactive oxygen species (ROSs), where NADPH produced at ICDH and the oxidative pentose phosphate pathways play an important role in coping with oxidative stress. Solvent resistant mechanism was also considered for the stresses caused by biofuels and biochemicals production in the cell.
\end{abstract}

Keywords: metabolic regulation; nutrient limitation; environmental stress; intracellular metabolite; global regulators; enzyme level regulation; transcriptional regulation 


\section{Abbreviations}

PP pathway: pentose phosphate pathway; TCA cycle: tricarboxylic acid cycle; PTS: phosphotransferase system; EI: enzyme I; EII: enzyme II; HPr: histidine-phosphorylatable protein; Cya: adenylate cyclase; CIT: citrate; E4P: erythrose-4-phosphate; FDP: fructose-1,6-bisphosphate; F6P, fructose-6-phosphate; G6P, glucose-6-phosphate; GAP: glycelaldehyde-3-phosphate; GLC: glucose; GOX: glyoxylate; ICI: isocitrate; KDPG: 2-keto-3-deoxy-6-phosphogluconate; $\alpha \mathrm{KG}$ : $\alpha$-ketoglutarate; MAL: malate; OAA: oxaloacetate; PEP: phosphoenol pyruvate; 6PG: 6-phosphogluconate; PYR: pyruvate; R5P: ribose-5-phosphate; RU5P: ribulose-5-phosphate; S7P: sedoheptulose-7-phosphate; SUC: succinate; X5P: xylulose-5-phosphate; Ack: acetate kinase; Acs: acetyl coenzyme A synthetase; Adk: adenylate kinase; Ald: aldolase; CS: citrate synthase; Eno: enolase; Fum: fumarase; G6PDH: glucose-6-phosphate dehydrogenase; GAPDH: glyceraldehyde-3-phosphate dehydrogenase; ICDH: isocitrate dehydrogenase; Icl: isocitrate lyase; LDH: lactate dehydrogenase; MDH: malate dehydrogenase; Mez: malic enzyme; MS: malate synthase; Pck: phosphoenolpyruvate carboxykinase; PDH: pyruvate dehydrogenase; Pfk: phosphofructokinase; PGDH: 6-phosphogluconate dehydrogenase; Pgi: phosphoglucose isomerase; Pgk: phosphoglycerate kinase; Ppc: phosphoenolpyruvate carboxylase; Pps: phosphoenolpyruvate synthase; Pta: phosphotransacetylase, Pyk: pyruvate kinase; Ru5P: ribulose phosphate epimerase; R5PI: ribose phosphate isomerase; SDH: succinate dehydrogenase; SOD: superoxide dismutase; Tal: transaldolase; Tkt: transketolase.

\section{Introduction}

Living organism must survive in response to a variety of environmental perturbations. For this, living organisms sense environmental changes by detecting extracellular signals such as the concentrations of nutrients such as carbon, nitrogen, phosphate, sulfur, ion sources, and the growth conditions such as $\mathrm{pH}$, temperature, oxygen availability or oxidative stress, osmotic stress, and solvent stress. These signals eventually feed into the transcriptional regulatory systems, which affect the physiological and morphological changes that enable organisms to adapt effectively for survival [1].

Since environmental perturbations occur simultaneously, cells must recognize the changes, integrate such information, and adjust the metabolism systematically. To understand how the cell system regulates for the variety of perturbations, or how the cells integrate such information, local molecular knowledge alone may not be sufficient. Instead, it is important to understand how the cell system's behavior emerges from interactions between characterized molecules [2,3]. To understand such mechanisms, the coupling between recognition and adjustment aspects, and between enzyme regulation and gene level regulation must be understood in the network context [4].

Biological systems are known to be robust and adaptable to culture environment. Such robustness is inherent in the biochemical and genetic networks. Several genes that are necessary to respond to various environmental or nutritional changes require specific recognition by RNA polymerase associated with alternative sigma factors. Here, we consider how environmental changes are detected through signaling systems by modulating appropriate transcription factors, how the metabolic pathway genes are regulated by the corresponding transcription factors, and how the metabolism changes. 
Living organisms such as bacterial cells have complex but efficient mechanisms to respond to the change in culture environment. This is mainly achieved by the so-called global regulators, where they generally act at transcriptional level. A two-component signal transduction system is considered to be the important means of detecting extracellular signals and transducing the signals into cytosol for metabolic regulation. These involve a phospho-relay from a transmembrane histidine protein kinase sensor to the target response regulator. In the case of E. coli, 29 transcription factors (TFs) show such regulation with 28 histidine protein kinase [5], where the genes encoding the two components are usually located within the same operon, enabling their coordinated expression. Note that there might exist a cross-talk between noncognate sensors and regulators [6].

In addition to exogenous signals, the cell can recognize the cell's state by detecting the intracellular metabolites. The typical example is catabolite repressor/activator protein Cra (originally called fructose repressor protein FruR) which binds a key intermediate such as fructose 1,6-bis phosphate (F1, 6BP or FDP) and regulates the carbon flow (Figure 1a). FDP plays an important role in flux sensing, which will be mentioned later. There exists a hybrid type of TFs where they sense the metabolites that are transported from the culture environment or synthesized endogenously. This can typically be seen in regulating amino acid synthetic pathways, possibly because it is preferable for the cell to import essential metabolites when they are freely available rather than expend energy on their production [1].

In relation to global regulators, sigma factors also play important roles, where they allow RNA polymerase to be recruited at specific DNA sequences in the promoter regions at which they initiate transcription. In E. coli, seven sigma factors have been found so far, and these play important roles depending on the environmental stimuli $\left(\sigma^{19}\right.$ : ion transport, $\sigma^{24}$ : extreme temperature, $\sigma^{28}$ : flagella genes, $\sigma^{32}$ : heat shock, $\sigma^{38}$ : stationary phase or carbon starvation etc., $\sigma^{54}$ : nitrogen regulation, $\sigma^{70}$ : house keeping) [7]. H-NS (histone-like nucleotide structuring protein) is another type of global transcriptional regulator, which regulates a variety of physiological functions such as metabolism, fimbriae expression, virulence flagella synthesis, and proper function [8].

Other types of global regulators are signaling molecules such as cyclic-AMP (cAMP) and cyclic-di-GMP (bis-(3'-5')-cyclic-dimeric guanosine monophosphate) [9,10]. The cAMP is synthesized from ATP by Cya (adenylate cyclase) at low glucose concentration with an increase in phosphorylated EIIA $^{\text {Glc }}$ (EIIA ${ }^{\text {Glc }}$-P) involved in phosphotransferase system (PTS)(Figure 1b), where EIIA ${ }^{\text {Glc }}$-P activates Cya activity. The cAMP binds to Crp (cAMP receptor protein), also known as CAP (catabolite activation protein), and cAMP-Crp complex becomes an activated transcription factor in relation to catabolite regulation as will be explained in more detail later. Note that cAMP regulates not only catabolite regulation, but also flagellum synthesis, biofilm formation, quorum sensing, and nitrogen regulation [10-13].

As another level of regulation, small noncoding RNAs (sRNAs) play important roles in the post-transcriptional regulation [14]. The sRNAs are mainly involved in stress response regulation, pathogenesis, and virulence. A single sRNA can affect multiple targets, where sRNAs modify the translation or stability of the targets and chaperone. One such example is SgrS in E. coli, where it binds to mRNA of $p t s G$ gene, which encodes $\mathrm{EIICB}^{\mathrm{Glc}}$ for glucose uptake [15]. Another group of sRNAs bind to proteins, where such example is CsrB in E. coli [16], and these sRNAs regulate the activity of CsrA, a global regulator for carbon storage regulation. The sRNAs are involved in the fine-tuning of gene expression by binding to target mRNAs with mediation of the RNA chaperon Hfq $[17,18]$. This 
expression depends on the specific environmental conditions such as oxidative stress, cell envelope homeostasis, and glucose starvation [19].

Figure 1. Main metabolic pathways and its regulation: (a) Control by TFs such as Cra; and (b) transport of glucose via PTS and non-PTS transporters.

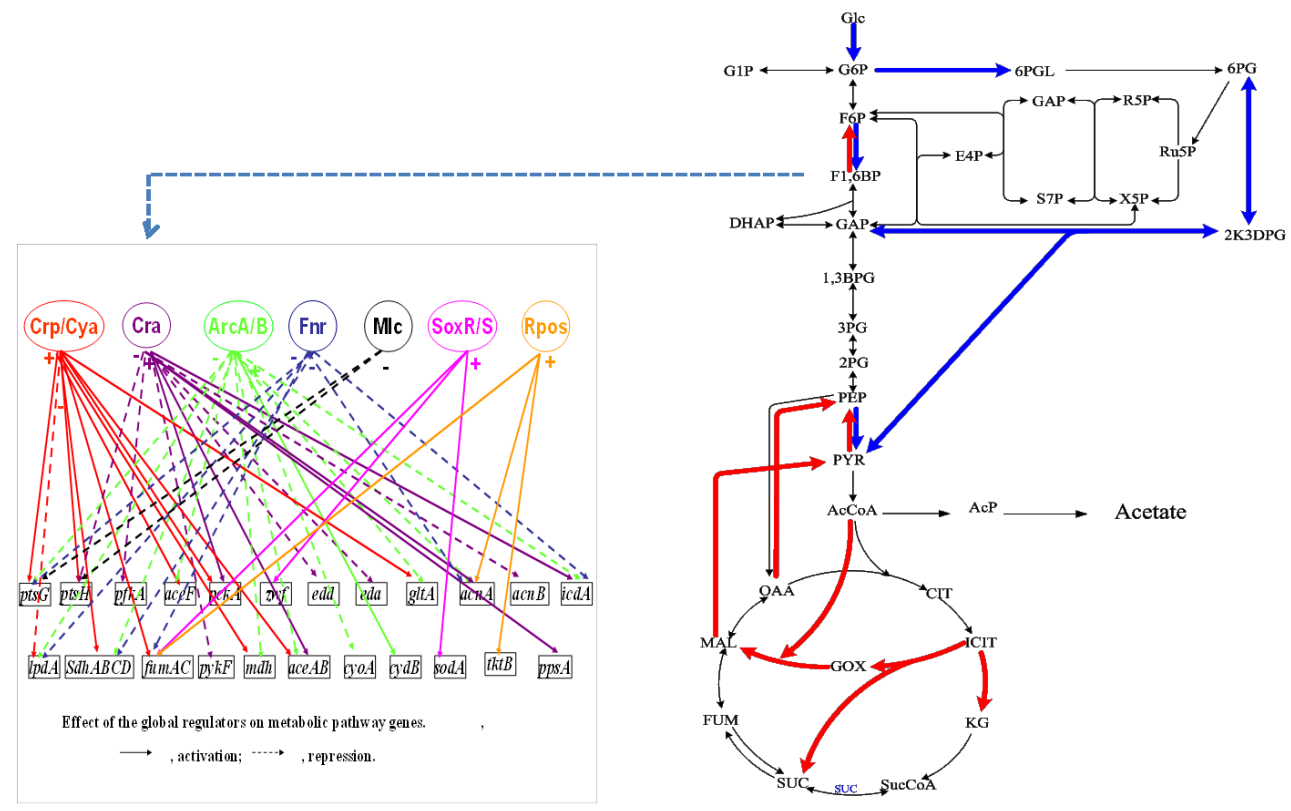

(a)

\section{Glucose}

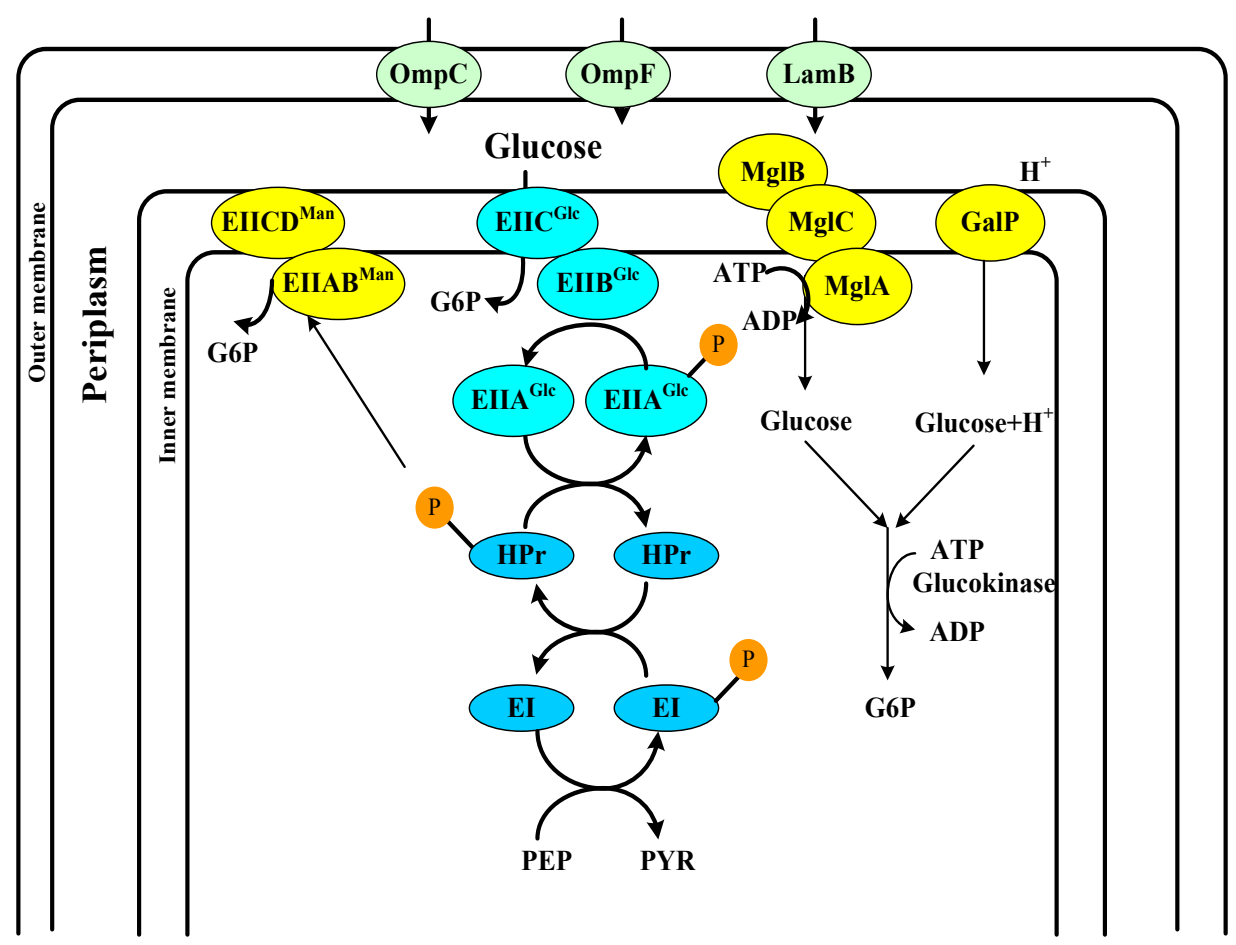

(b) 
Metabolic regulation mechanism is quite complex [20,21], but a wide variety of data are accumulating together with molecular and biological knowledge, and it is desirable to appropriately understand the regulation mechanism of the whole cell system. Below, an attempt is made to overview the regulation mechanism in response to the variety of culture environmental perturbations, keeping in mind the basic schemes as mentioned above for bacterial cells, in particular for E.coli.

\section{Transport of Nutrient Molecules and PTS}

Microorganisms must uptake nutrients from the external environment, where it is critical to transport the nutrients rapidly across cell membranes and maintain enough nutrient levels in the cytoplasm. Some of the nutrients, such as $\mathrm{CO}_{2}$ or $\mathrm{NH}_{3}$, can diffuse across membrane somewhat faster than water [22,23]. The driving force for such transport is the concentration differences between cytosol and external environment. Large membrane permeability gives the benefit of high ambient nutrient levels, where passive diffusion alone can supply enough nutrients for the cell growth without spending energy. On the other hand, if ambient nutrient level is low, intracellular nutrient may diffuse out, and thus active transport system must function to pump in scarce nutrient present in the external environment for survival. Those examples are AmtB to capture scarce ammonium, Pst system to capture scarce phosphate, as will be explained later in more detail.

The gram-negative bacteria such as $E$. coli have outer membrane and inner cytoplasmic membrane, which act as hydrophobic barrier against polar compounds. The outer membrane contains channel proteins, where the specific molecules can only move across these channels. In the outer membrane of E. coli, 108 channels are formed by porin proteins [24], These are open but regulated water-filled pores that form substrate-specific, ion-selective, or nonspecific channels that allow the influx of small hydrophilic nutrient molecules and the efflux of waste products [25]. They also exclude many antibiotics and inhibitors that are large and lipophilic [26]. The OmpC and OmpF are the most abundant porins present under typical growth conditions [27]. Their relative abundance changes depending on osmolarity, temperature, and growth phase. Under glucose limitation, outer membrane glycoporin LamB is induced [28], where this protein permeates such carbohydrates as maltose, maltodextrins, and glucose [29].

Porin genes are under the control of the two-component EnvZ-OmpR system, where EnvZ is an inner membrane sensor kinase and $\mathrm{OmpR}$ is the cytoplasmic response regulator. Figure 2 shows how porin genes are regulated by two-component systems. In response to osmolarity, $\mathrm{pH}$, temperature, nutrients, and toxins, EnvZ phosphorylates OmpR, where the phosphorylated OmpR (OmpR-P) regulates porin genes [25]. Acetyl phosphate (AcP) can function as a phosphate donor for OmpR under certain condition. OmpR controls cellular processes such as chemotaxis and virulence as well [30]. In terms of virulence, abolition of porin formation diminishes pathogenesis [25]. 
Figure 2. Regulation of porin genes in response to culture environment.

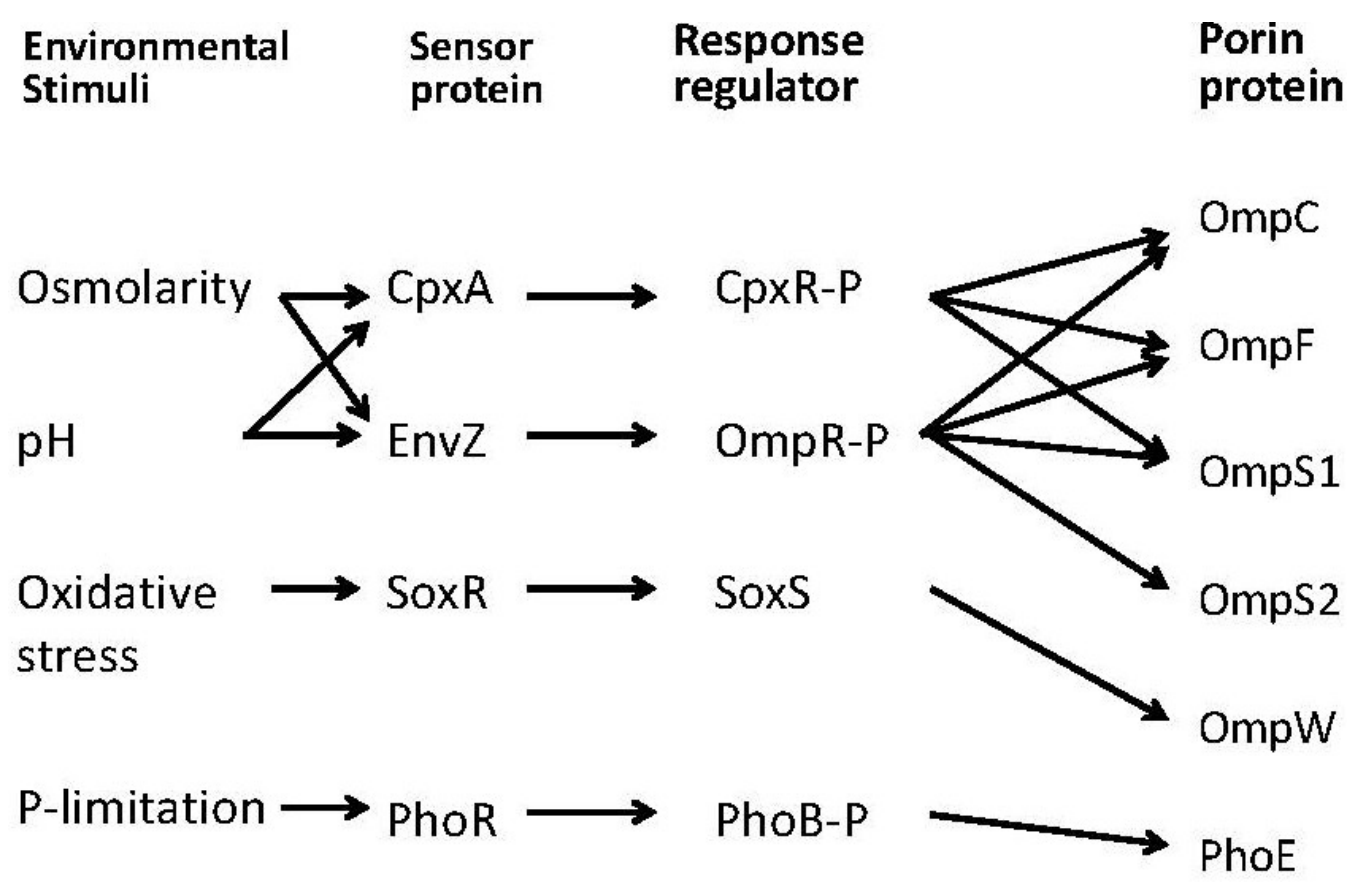

The first step in the metabolism of carbohydrates is the transport of these molecules into cytosol. In bacteria, various carbohydrates are taken up by several mechanisms [31]. The most common mechanism is the transport by phosphotransferarse system (PTS), where glucose can be transported from periplasm into cytosol, where PTS is widespread in bacteria and absent in archaea and eukaryotic organisms [32]. PTS is composed of soluble and nonsugar-specific components, Enzyme I (EI) encoded by $p t s I$ and phosphohistidine carrier protein (HPr) encoded by $p t s H$, where they transfer phosphoryl group from phosphoenol pyruvate (PEP) produced in the main metabolism to the sugar-specific enzyme IIA and IIB. Another component of PTS is enzyme IIC (in some cases also IID) which is an integral membrane protein permease that transports sugar molecules, where it is phosphorylated by EIIB (Figure 1b). So far, 21 different EII complexes have been identified in E. coli, and those are involved in the transport of about 20 different carbohydrates such as glucose, fructose, mannose, mannitol, galactitol, sorbitol etc. [33]. In E. coli, glucose can be transported by EII ${ }^{\mathrm{Glc}}$ and EII $^{\mathrm{Man}}$. The EII ${ }^{\mathrm{Glc}}$ is composed of soluble EIIA ${ }^{\mathrm{Glc}}$ encoded by $\mathrm{crr}$ and of integral membrane permease EIICB $^{\text {Glc }}$ encoded by ptsG.

In $p t s G$ mutant, glucose can be transported by EII ${ }^{\mathrm{Man}}$ complex, and the cell can grow with less growth rate than the wild-type strain [34]. Under glucose limitation, galP is induced, where it codes for low-affinity galactose: $\mathrm{H}^{+}$symporter GalP. The genes in the $m g l A B C$ operon encode an ATP-binding protein, a galactose/glucose periplasmic binding protein, and an integral membrane transporter protein, respectively, forming $\mathrm{Mgl}$ system for galactose/glucose import [35] (Figure 1b). When extracellular glucose concentration is very low, the Mgl system together with LamB attains high-affinity glucose transport [35]. The glucose molecule transported either by the GalP or Mgl systems must be phosphorylated by glucokinase (Glk) encoded by glk from ATP to become glucose 6-phosphate (G6P) [36] (Figure 1b).

The non-PTS carbohydrates such as xylose, glycerol, galactose, lactose, arabinose, rhamnose, maltose, melibiose, and fucose are recognized through TFs. Neither trans-membrane sensors nor 
regulatory proteins with sensing function have been identified so far for organic acids such as acetate, succinate, or malate, and it is unclear how these carbon sources are recognized [4], while formate is transported by Foc.

\section{Flux Sensor}

In addition to the canonical nutrient sensors, which measure the concentrations of nutrients, the concept of flux sensor may be useful as a novel impetus for metabolic regulation, where the metabolic fluxes may be sensed by molecular systems as flux sensors [4,37,38]. Namely, if there is a strong (linear) relationship between the specific flux and the specific metabolite concentration, flux changes can be detected by the corresponding metabolite concentration. For example, the fluxes of lower glycolysis and the feedforward activation of FDP on Pyk show such characteristics (Figure 3a). Moreover, the interaction of this flux-signaling metabolite with Cra then leads to flux-dependent regulation (Figure 3a). Instead of utilizing nutrient specific receptors to sense the environmental signals, which require the simultaneous expression of a large number of receptors, and impose a large burden on the cell, the flux-sensing system simply recognizes the fluxes by the intracellular metabolite as integral signal. Since the relationship between FDP and the lower part of glycolysis flux depends on the allosteric regulation of FDP on Pyk, this relationship may not hold for certain mutants such as pyk mutant.

In general, there might be a correlation between a certain metabolic flux and a particular phenotype based on flux-dependent regulation. For example, there is a relationship between the specific glucose uptake rate and the activities of the respiratory and fermentative pathways. Namely, there is a correlation between the specific glucose uptake rate and the ethanol production rate in the cultivation of Saccharomyces cerevisiae, whereas there is no correlation between the specific growth rate and the ethanol production rate [37]. In the case of E.coli, acetate production has been considered to be an overflow metabolism with respect to the specific growth rate (or the dilution rate in the continuous D-stat culture or accelerating A-stat culture) [39-41]. As far as wild type strain is considered, the specific growth rate is correlated with the specific glucose uptake rate by the yield coefficient [42]. However, if we consider the case of nitrogen limitation [43], the specific acetate production rate is not correlated with the cell growth rate, but may correlate with the specific glucose uptake rate. As the specific glucose uptake rate increases in accordance with the specific growth rate, the phosphorylated $\mathrm{E} \mathrm{II} \mathrm{A}^{\mathrm{Glc}}$ (E II A ${ }^{\mathrm{Glc}}$-P) decreases $[44,45]$, which in turn decreases the activity of Cya, and cAMP level as well as cAMP-Crp level decreases (Figure 3b). The decreased cAMP-Crp represses the glucose uptake rate by the decreased expression of $p t s G$, which forms the feedback regulation to the initial increase in the glucose uptake rate [46] (Figure 3). Figure 4 shows how the categorized gene expression changes with respect to the dilution rate (the specific growth rate) [47,48]. Figure $4 \mathrm{a}$ abd $4 \mathrm{c}$ shows that the decrease in cAMP-Crp transcriptionally represses the TCA cycle gene expression as the cell growth rate or the specific glucose consumption rate increases $[39,47,48]$. Although the TCA cycle gene expression is repressed, and the relative flux in \% decreases with respect to the specific glucose consumption rate [41,47] (Figure 4e), the absolute flux on the mmol basis may increase due to increased glucose up-take rate [47]. Consider why the TCA cycle has to be transcriptionally repressed. As mentioned above, the specific NADH production rate increases as TCA cycle activity increases, which in turn activates the respiration as far as enough oxygen is available. However, this causes a 
high possibility of producing oxygen radicals, which gives the critical damage to the cell, where this is protected by such transcription factors as OxyR and SoxR/S affecting the expression of such genes as sodA and catA as will be explained later in the section of oxidative stress. Thus, it may be presumed that the TCA cycle has an upper bound to avoid the production of oxygen radicals. Note that the minimum TCA cycle flux is always needed to supply $\alpha$ keto glutarate $(\alpha K G)$ for ammonium assimilation via glutamate dehydrogenase (GDH) to form glutamate (and also glutamine), and then the nitrogen source $(\mathrm{N})$ is spread around other amino acids by subsequent transanimations.

Figure 3. Feedforward and feedback controles by enzyme level and transcriptional regulations: (a) regulation by $\mathrm{Cra}$, and (b) regulation by cAMP-Crp.

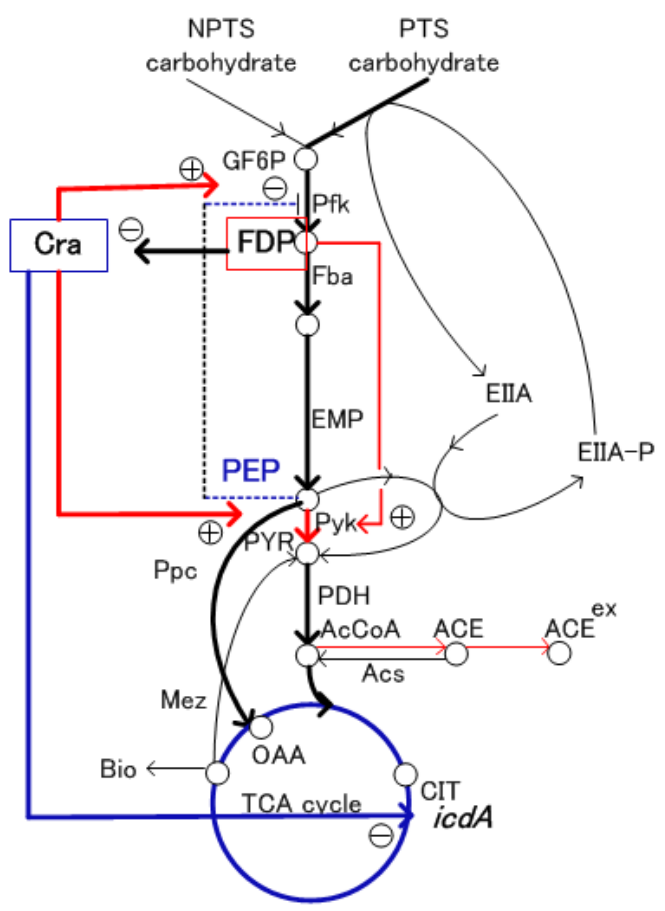

(a)

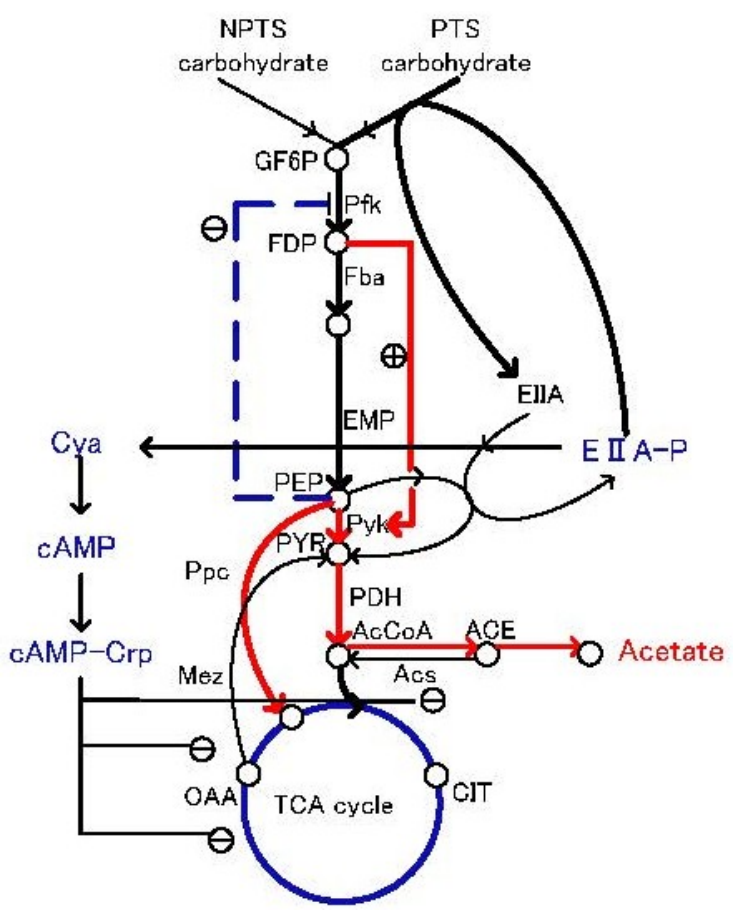

(b)

It may be considered that the dominance of catabolite regulation overrides many other regulation processes via crp, where the most relevant control mechanism is cAMP-dependent catabolite repression of the PEP-glyoxylate cycle with low TCA cycle fluxes based on ${ }^{13} \mathrm{C}$-flux analysis of $E$. coli mutants [42]. In the cya and crp mutants that lack cAMP-Crp complex, glyoxylate shunt activity is essentially abolished, and such cycle will not appear.

In the case of carbon starvation, AMP and PEP increase for both E.coli and Yeast [49]. Note that cAMP is not the starvation signal for Yeast, while it is for E.coli. AMP may reflect energy limitation for both organisms, where AMP is in equilibrium with ADP to ATP ratio by adenylate kinase Adk [49]. In both organisms, PEP level increases under carbon starvation, where Pyk is allosterically deactivated by the decrease in FDP, a positive feedforward regulator as mentioned above (Figure 3a). The increased PEP in turn inhibits Pfk activity, reinforcing the blockage of glycolysis, and then reduces the glucose uptake rate. In the case of E.coli, the decrease in FDP further activates Cra activity, and transcriptionally represses $p f k A$ and $p y k F$ gene expression (Figure 3a). Moreover, the 
increase in PEP concentration and thus PEP/PYR ratio increases phosphorylation of $\mathrm{E}$ II A and activates Cya, resulting in the increase in cAMP level in E.coli, while it is kept low in the case of Yeast.

Figure 4. Effect of the growth rate (dilution rate in the continuous culture) on gene expression and fluxes: (a) global regulators, (b) glycolysis genes, (c) TCA cycle genes, (d) PP pathway genes, and (e) TCA cycle fluxes and acetate formation rate. Open symbol from [47], while filled symbol from [48].

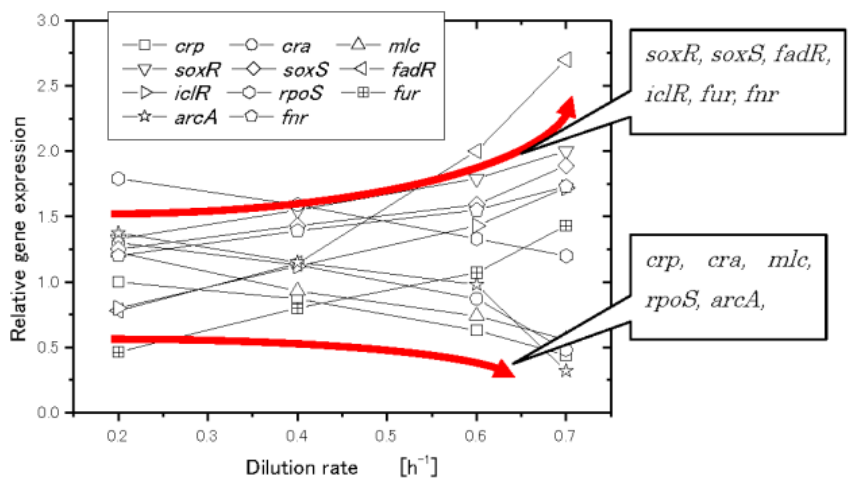

(a) Global regulatory genes

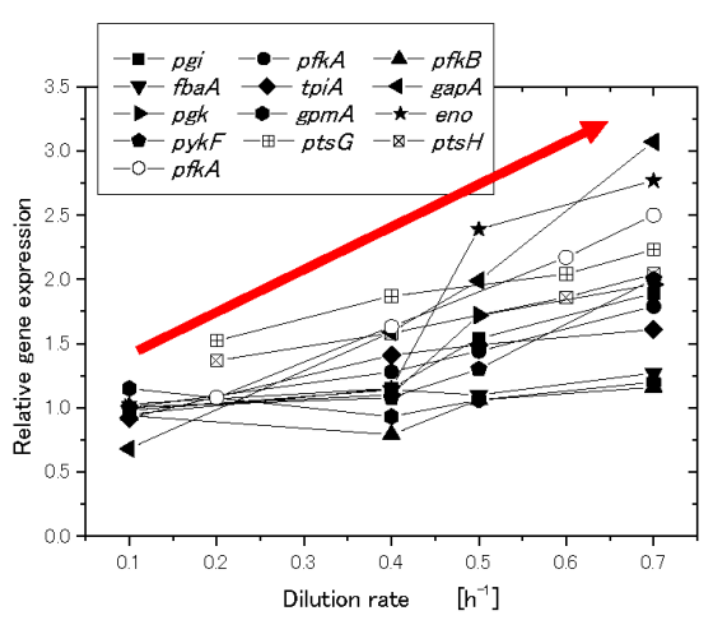

(b) Glycolysis gene expression

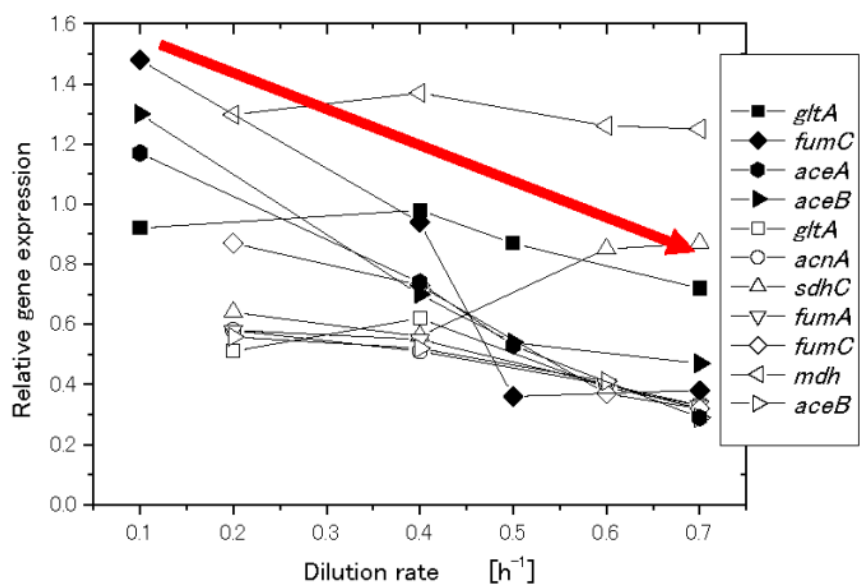

(d) TCA cycle gene expression

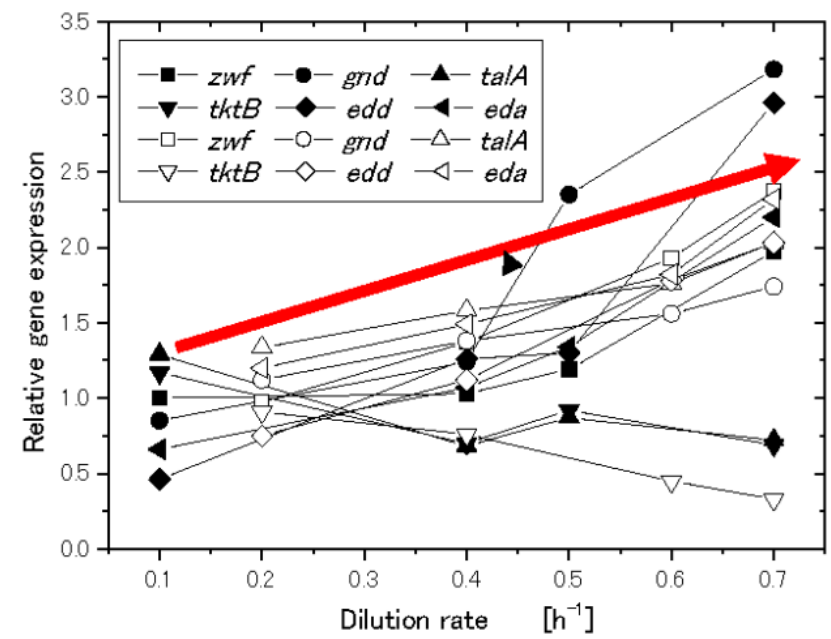

(c) PP patheway gene expression

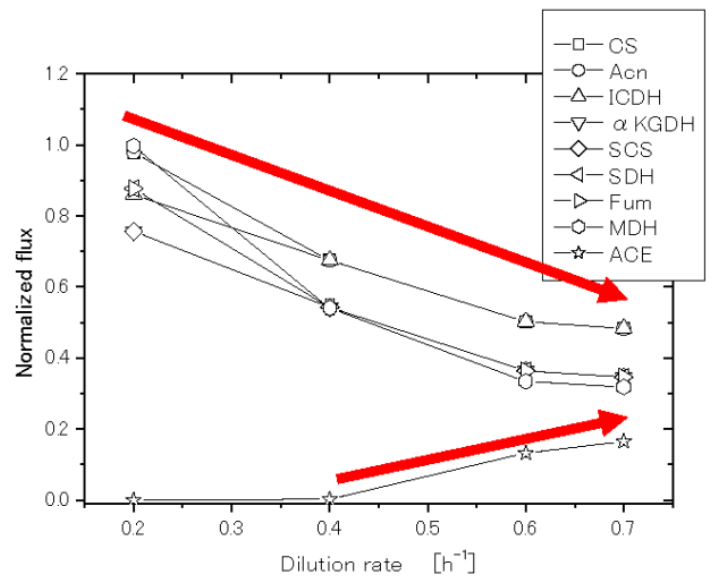

(e) TCA cycle fluxes and acetate formation rate 
One of the most important metabolic rearrangements is the transition from glycolytic to gluconeogenetic carbon sources that involve redirection of the carbon flow through the main metabolic pathways at the late growth phase or early stationary phase in the batch culture. This phenomenon is wide-spread to various organisms. This diauxic shift in $S$. cerevisiae is accomplished by the following three events: (1) a reduction in the glycolytic flux with production of storage compounds before glucose depletion, (2) upon glucose exhaustion, the reversion of carbon flow through glycosis with activation of the glyoxylate pathway, and (3) shutting down of the pentose phosphate (PP) pathway with a change in NADPH regeneration in the later stages [50].

\section{Carbon Storage Regulation}

The carbon storage regulator (Csr) system influences a variety of physiological processes such as central carbon metabolism, biofilm formation, motility, peptide uptake, virulence and pathogenesis, quorum sensing, and oxidative stress response [8,51-53]. Csr is controlled by the RNA-binding protein CsrA, a posttranscriptional global regulator that regulates mRNA stability and translation [54-56], where CsrA is regulated by two sRNAs such as CsrB and CsrC [57-59]. CsrA represses glycogen accumulation by regulating the expression of $\operatorname{glg} C A P$ operon and $\operatorname{glg} B$ of $g \lg B X$ operon $[8,60]$. CsrA regulates the central carbon metabolism and glycogenesis such that glycogen synthesis pathway genes, as well as gluconeogenic pathway genes are repressed, while glycolysis genes are activated $[8,61]$ (Supplementary Table S1).

From the practical application point of view, phenylalanine production can be enhanced by manipulation of Csr, where $\operatorname{csr} A$ mutation causes a significant increase in intracellular PEP concentration, since CsrA positively regulates $p y k F$, while negatively regulates $p c k A$ and $p p s A$. The precursor of shikimate pathway for aromatic amino acids production are a single E4P and two PEP molecules, and thus over-expression of $t k t A$ with $\operatorname{csr} A$ gene disruption enhances phenylalanine biosynthesis [62].

The biofuels production can be improved by the over-expression of CsrB by activating native fatty acid and heterologous n-butanol and isoprenoid pathways [61]. In particular, CsrB-mediated degradation of CsrA drives over-expression of $g \lg C A P$ operon, which results in the accretion of the storage polysaccharide glycogen. AcCoA and several amino acid concentrations increase with concurrent decrease in acetate level with this mutation [61]. Moreover, CsrB impacts the expression of the stringent response regulator DksA, where it is responsible for transcriptional activation of $\mathrm{CsrB}$ during stringent response [63]. This suggests that CsrB directly regulates DksA through CsrA, thereby forming a positive feedback loop, indicating the links between CsrA/B and the stringent response [61,63].

\section{Nitrogen Regulation}

Next to carbon (C) source metabolism, nitrogen $(\mathrm{N})$ metabolism is also important in understanding the metabolic regulation. In E. coli, assimilation of N-source such as ammonia/ ammonium $\left(\mathrm{NH}_{4}{ }^{+}\right)$ using $\alpha-\mathrm{KG}$ results in the synthesis of glutamate and glutamine (Figure 5). Glutamine synthetase (GS, encoded by $g \ln A$ ) catalyzes the only pathway for glutamine biosynthesis. Glutamate can be synthesized by two pathways through the combined actions of GS and glutamate synthase (GOGAT, encoded by $g l t B D$ ) forming GS/GOGAT cycle, or by glutamate dehydrogenase (GDH encoded by $g d h A$ ) [64] (Figure 5). When extracellular $\mathrm{NH}_{4}{ }^{+}$concentration is low around $5 \mu \mathrm{M}$ or less, ammonium 
enters into the cell via AmtB, and is converted to glutamine by GS, and UTase (uridylyl transferase) uridylylates both GlnK and GlnB [65](Figure 5). When extracellular $\mathrm{NH}_{4}{ }^{+}$concentration is more than $50 \mu \mathrm{M}$, the metabolic demand for glutamine pool rises, and UTase deuridylylates GlnK and GlnB. GlnK complexes with $\mathrm{AmtB}$, thereby inhibiting the transport via AmtB, where GlnB interacts with $\mathrm{NtrB}$ and activates its phosphatase activity leading to dephosphorylation of NtrC, and NtrC-dependent gene expression ceases [65].

Figure 5. $\mathrm{NH}_{3}$ assimilation pathways and the regulation under $\mathrm{N}$-limitation.

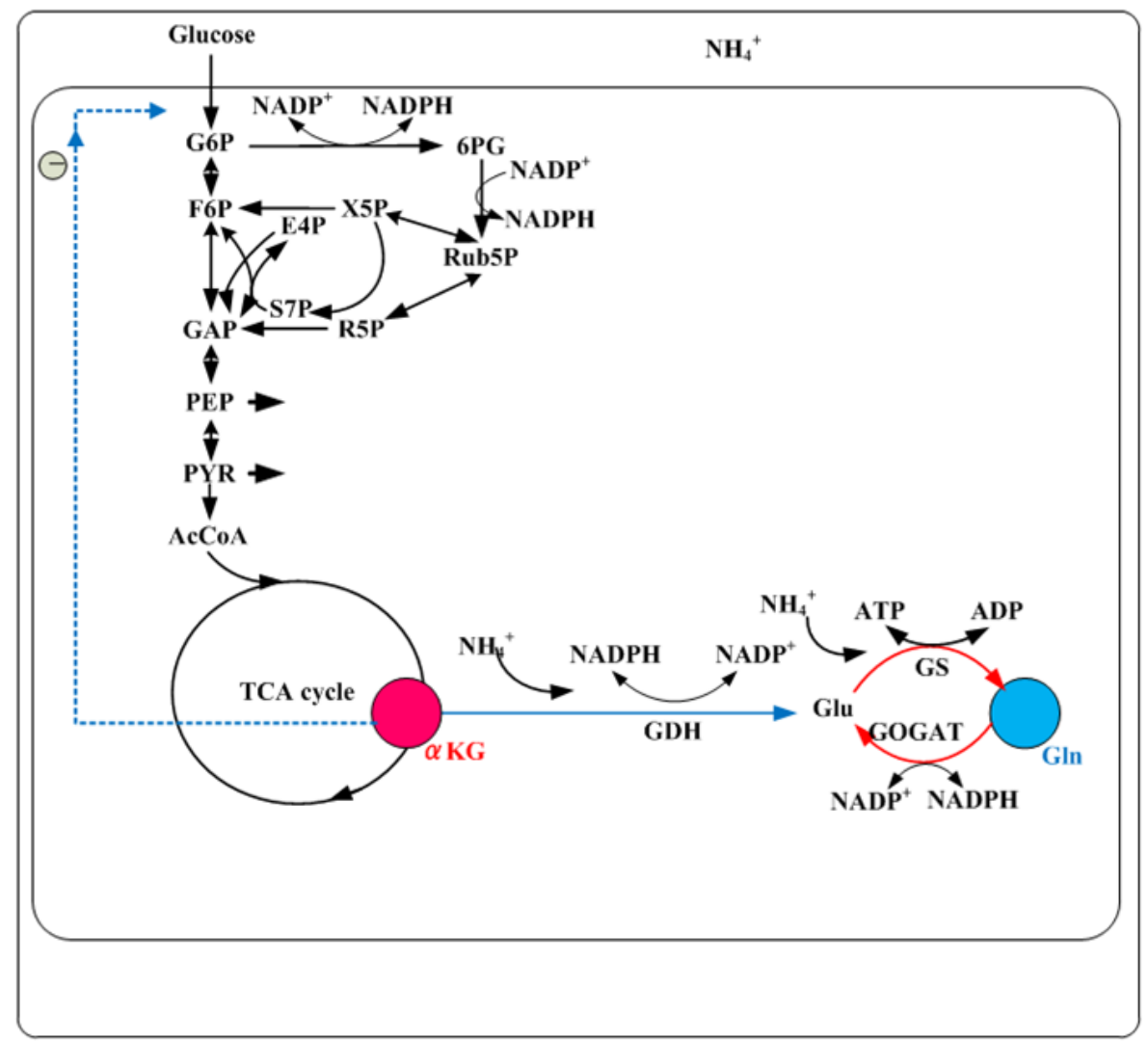

GlnK binds to AmtB and inhibits its activity under ammonium rich conditions, while GlnK dissociates from AmtB at low ammonium concentration, thereby setting AmtB free to act for ammonium transport [66-68] (Figure 5). Intracellular ammonium is assimilated into biomass in two steps: Namely, it is first captured in the form of glutamic acid (Glu) using carbon skeleton of $\alpha \mathrm{KG}$ via GS/GOGAT cycle. Then N-group in Glu is transferred to synthesize amino acids thus incorporating into biomass, while recycling the carbon skeleton back to $\alpha \mathrm{KG}$ [69]. The $\alpha \mathrm{KG}$ pool, which integrates imbalance between the ammonium assimilation flux and the biomass incorporation flux activates AmtB [66-68] via GlnK. If the internal ammonium level drops, then the rate of ammonium assimilation will drop immediately. This results in $\alpha \mathrm{KG}$ accumulation [70] (Figure 5).

From the studies on interdependence of different metabolic routes, two of the major signal transduction systems of $\mathrm{N}$ and $\mathrm{C}$ metabolisms have been identified as $\mathrm{P}_{\mathrm{II}}$, a small nitrogen regulatory protein and PTS. Because of the important roles in the regulatory functions, $\mathrm{P}_{\text {II }}$ and PTS can be regarded as the central processing units of $\mathrm{N}$ and $\mathrm{C}$ metabolisms, respectively. The $\mathrm{P}_{\text {II }}$ protein senses $\alpha \mathrm{KG}$ and ATP, thus link the state of central carbon and energy metabolism for the control of $\mathrm{N}$ 
assimilation [71]. The glucose catabolism is modulated by the global regulators such as Cra, Crp, Cya, and Mlc as mentioned before, while $\mathrm{N}$ assimilation is regulated by $\mathrm{P}_{\mathrm{II}}-\mathrm{Ntr}$ system together with $\mathrm{Crp}$, providing a regulatory network between $\mathrm{C}$ and $\mathrm{N}$ assimilation in E. coli [72]. The $\mathrm{C}$ and $\mathrm{N}$ metabolisms may be linked by energy metabolism, where $\mathrm{P}_{\mathrm{II}}$ protein controls $\mathrm{N}$ assimilation by acting as a sensor of adenylate energy charge, which is the measure of energy available for the metabolism. Moreover, $\alpha \mathrm{KG}$ serves as a cellular signal of $\mathrm{C}$ and $\mathrm{N}$ status, and strongly regulates $\mathrm{P}_{\mathrm{II}}$ functions [73]. Gln and $\alpha \mathrm{KG}$ are the signal metabolites for nitrogen and carbon status, respectively, and these signals regulate GS adenylylation state and nitrogen regulator I ( $\mathrm{NR}_{\mathrm{I}}$ or $\left.\mathrm{NtrC}\right)$ phosphorylation state [74]. Nitrogen shortage is reflected by the reduced Gln levels and increased $\alpha \mathrm{KG}$ level [49,70] (Figure 5). While the ratio of Gln to $\alpha \mathrm{KG}$ varies in response to N-limitation, this ratio is substantially constant under $\mathrm{C}$-limitation. This constant ratio requires tuning the rate of ammonia assimilation to match exactly the carbon uptake rate. This ratio is insensitive to variations in protein levels of the core circuit and to the N-utilization rate, and this robustness depends on bifunctional enzyme adenylyl transferase [75].

During N-limitation, a sudden increase in nitrogen availability results in immediate increase in glucose uptake, and $\alpha \mathrm{KG}$ plays an important role for this, where $\alpha \mathrm{KG}$ directly blocks the glucose uptake under N-limitation by inhibiting EI of PTS [76] (Figure 5). This implies several things: (1) $\alpha \mathrm{KG}$ inhibition of sugar uptake is for all PTS sugars by inhibiting EI but not carbohydrate specific E, (2) this is performed without perturbing the concentrations of the glycolytic intermediates such as G6P, PEP, and PYR, (3) inhibition of EI by $\alpha \mathrm{KG}$ leads to reduced amount of phosphorylated E II AGlc and decreases cAMP level, where the effect of $\alpha \mathrm{KG}$ on cAMP production is caused by the difference in $\mathrm{E} I \mathrm{~A} \mathrm{~A}^{\mathrm{Glc}}$ phosphorylation rather than a difference in substrate availability [76]. Moreover, $\alpha \mathrm{KG}$ is a promiscuous enzymatic regulator that competitively inhibits CS of the TCA cycle and 3PG dehydrogenase for serine biosynthesis, and further controls aspartate production by product inhibition of transaminase under N-limitation [76]. Note that $\alpha \mathrm{KG}$ noncompetitively inhibits EI and Pps, while PtsP (EI homolog in the nitrogen PTS, which will be mentioned next) is insensitive to $\alpha \mathrm{KG}$.

\section{The Role of PTS ${ }^{\mathrm{Ntr}}$}

In addition to carbohydrate PTS, most proteobacteria possess a paralogous system such as nitrogen phosphotransferase system PTS ${ }^{\mathrm{Ntr}}$, where it consists of $\mathrm{EI}^{\mathrm{Ntr}}$ encoded by $p t s P$, NPr encoded by $p t s O$, and EII $\mathrm{A}^{\mathrm{Ntr}}$ encoded by ptsN, which are paralogues of the carbohydrate PTS components such as EI, HPr, E II A, respectively [77-79].

E.coli $\mathrm{PTS}^{\mathrm{Ntr}}$ plays a role in relation to $\mathrm{K}^{+}$uptake, where dephosphorylated E II ANtr binds to and regulates the low affinity $\mathrm{K}^{+}$transporter TrkA [80] and the $\mathrm{K}^{+}$-dependent sensor kinase $\mathrm{KdpD}[79,81]$. $\mathrm{K}^{+}$regulates global gene expression involving both $\sigma^{70}$ - and $\sigma \mathrm{S}$-dependent promoters [82]. Moreover, dephosphorylated $\mathrm{E} I I \mathrm{~A}^{\mathrm{Ntr}}$ modulates the phosphate starvation response through interaction with sensor kinase PhoR [83]. The dephosphorylated form of NPr interacts with and inhibits LpxD, which catalyses biosynthesis of lipidA of the lipopolysaccharide (LPS) layer [84].

Although the physiological role of Ntr has not been well known, glutamine and $\alpha \mathrm{KG}$, reciprocally regulate the phosphorylation state of the $\mathrm{PTS}^{\mathrm{Ntr}}$ by direct effects on $\mathrm{EI}^{\mathrm{Ntr}}$ auto-phosphorylation. This implies that PTS ${ }^{\mathrm{Ntr}}$ senses nitrogen availability [85]. 


\section{Regulation for S-limitation}

At least three metabolites such as (1) sulfide, the reduction product of sulfate, which is used for cystein biosynthesis, (2) N-acetylserine, the only precursor of cysteine, and (3) adenosine 5'-phosphosulphate (APS), the first intermediate in sulfate assimilation are involved in perceiving S-limitation [86,87]. The concentrations of sulfide and APS decrease, while N-acetylserine pool increases under S-limitation. The two regulators $\mathrm{CysB}$ and $\mathrm{Cbl}$ mediate homeostatic responses to S-limitation, where these responses help E.coli to scavenge trace amounts of cystein and sulfate, preferred $\mathrm{S}$ sources, or the alternative $\mathrm{S}$ sources such as glutathione and various alkaline sulfonate including taurin. S-limitation affects methionine metabolism, synthesis of FeS clusters, and oxidative stress.

Like NtrC for N-regulation, CysB is the primary regulator for homeostatic responses to $\mathrm{S}$, and it is required for the synthesis of $\mathrm{Cbl}$ [88]. CysB is positively controlled by $\mathrm{N}$-acetylserine and negatively controlled by sulfide or thiosulfate [87], and Cbl is negatively controlled by APS [86]. It is of interest that $c b l$ gene is transcribed from nac promoter under N-limitation [89]. The $d d p$ operon is activated by $\mathrm{NtrC}$, and there might be a cross regulation between S-limitation and N-limitation [90].

\section{Phosphate Regulation}

The phosphate $(\mathrm{P})$ metabolism is also quite important from the energy generation and phosphorelay regulation points of view. The phosphorous compounds serve as major building blocks of many biomolecules and have important roles in signal transduction [91]. Depending on the concentration of environmental phosphate, E. coli controls phosphate metabolism through Pho regulon, which forms a global regulatory circuit involved in a bacterial phosphate management [91,92]. The PhoR/PhoB two-component system plays an important role in detecting and responding to the changes of the environmental phosphate concentration [93].

When cells enter into $\mathrm{P}_{\mathrm{i}}$-starvation phase in the batch culture, the Pho regulon is activated, and $\sigma^{\mathrm{S}}$ starts to accumulate in the cytosol $[91,94,95]$. The promoters of the Pho genes are recognized by $\sigma^{\mathrm{D}}$-associated RNA polymerase. A mutation in $\operatorname{rpoS}$, significantly increases the level of AP (alkaline phosphatase) activity, and the overexpression of $\sigma^{\mathrm{S}}$ inhibits it [96]. Other Pho genes such as phoE and $u g p B$ are likewise affected by $\sigma^{\mathrm{S}}$. The RpoS may inhibit the transcriptions of $p h o A$, phoB, phoE, and $u g p B$, but not that of pstS [96]. The pst may be transcribed by both $\sigma^{\mathrm{S}}$ and $\sigma^{\mathrm{D}}$. The Pho regulon is thus evolved to maintain a tradeoff between cell nutrition and cell survival during $\mathrm{P}_{\mathrm{i}}$-starvation [96].

The Pho regulon and the stress response may be interrelated [95-100]. The presence of glucose or mutations in cya or crp leads to the induction of $p h o A$ gene in $p h o R$ mutatnt. This induction requires the sensor PhoM (CreC) and the regulator PhoB [101].

One $\mathrm{P}_{\mathrm{i}}$-independent control is the regulation by the synthesis of acetyl phosphate $(\mathrm{AcP})$, where $\mathrm{P}_{\mathrm{i}}$ is incorporated into ATP at Ack (acetate kinase) pathway. AcP may then act indirectly on PhoB.

\section{Regulation for Ion Uptake}

The metal levels are often sensed by metal-sensing regulatory RNA, which encodes metal-sensing proteins involved in the transport and storage of intra-cellular metals [102,103]. In the native environment, the cell such as E. coli continuously faces iron deficiency, where metal ion functions as 
cofactor in many of the cellular constituents such as flavoproteins, and therefore, the cell furnishes the mechanism for iron uptake and storage system [104,105]. However, excess iron causes toxicity by catalyzing the formation of reactive free radicals through Fenton/ Haber-Weiss reaction [106]. Aerobic respiration generates superoxide ions $\left(\mathrm{O}_{2}{ }^{-}\right)$, with $\mathrm{NDH}$ II as the main generator of endogenous superoxide and NDH I and SDH as small contributors [107]. In combination with inability to convert $\mathrm{NADH}$ to $\mathrm{NAD}^{+}$, a decrease in endogeneous $\mathrm{O}_{2}^{-}$causes reductive stress, and in turn activates Fur (ferric uptake regulator) [108]. Fur generally represses ion transport and ion siderophore biosynthetic genes when complexed with ferrous ion. Under ion limitation, ion dissociates from Fur, where Fur requires binding to $\mathrm{Fe}^{2+}$ to become active. $\mathrm{O}_{2}{ }^{-}$deactivates Fur after its conversion to $\mathrm{H}_{2} \mathrm{O}_{2}$ by superoxide dismutase (SOD), through Fenton reaction $\left(\mathrm{H}_{2} \mathrm{O}_{2}+\mathrm{Fe}^{2+} \rightarrow \mathrm{HO}+\mathrm{OH}^{-}+\mathrm{Fe}^{3+}\right)$ [109]. Therefore, a decrease in endogeneous $\mathrm{O}_{2}{ }^{-}$increases the availability of $\mathrm{Fe}^{2+}$, through a decrease in $\mathrm{H}_{2} \mathrm{O}_{2}$ level, and in effect activates Fur [110]. Namely, Fur senses the reductive stress and protect Fe-S clusters to be safe from damage by reactive oxygen species (ROS). It is essential for the cell to use iron economically, and this is attained by siderophores synthesis and iron transport regulation [111]. Iron transport and siderophores (e.g., enterobactin) pathway genes such as talB and entF are repressed by Fur [112-114], and enterobactin may be produced in fur mutant E.coli [115].

There are functional interactions between carbon and ion utilization via Crp and Fur, where many ion transport genes and several catabolic genes are subject to dual control. The $\operatorname{sod} B$ gene encoding SOD and ace $B A K$ operon show opposite responses, being activated by the loss of Crp, and repressed by the loss of Fur, while such genes as $s d h C D A B$, sucABCD, and fumA genes in the TCA cycle are repressed by the loss of both TFs. Moreover, the loss of two TFs activates a heterogenous group of genes encoding Cfa, cyclopropane fatty acid synthase, and $\mathrm{YggB}$, the mechanosensitive channel protein [116].

\section{Growth-Phase Dependent Fis Expression}

In E.coli, Fis (factor for inversion stimulation) is a nucleotide-associated protein, and is the most abundant during exponential growth phase [117]. Fis levels peak during early growth phase, and thereafter decrease until they become very low during stationary phase [118], where fis transcription is repressed by the stringent response [119], and fis is subject to growth rate control [120]. Moreover, the stringent control and the growth control all require the transcription factor DksA [120]. Fis seems to play a widespread role in signaling conditions of high nutritional control and outfitting the cells for efficient nutrient uptake, and rapid growth [118]. Fis also plays a role in signaling poor nutritional condition, where in response to amino acid starvation, fis is subject to severe and rapid negative control by the stringent response [120]. In relation to stringent response, (p)ppGpp and DksA interact with RNAP [121].

\section{Stringent Response to Nutrient Starvation}

The nutrient limitation may be defined as hunger and starved conditions, where the hunger state is defined to be in-between feast (nutrient excess) and famine (starvation or without nutrient) [122]. Bacteria generally have distinct strategies for the starvation in different nutrient sources. The individual hunger responses may be superimposed on a common protective starvation response [122]. 
Carbon limitation finally leads to amino acid limitation, which requires the signaling pathways via RelA and SpoT during carbon and amino acid limitation [123]. During stringent response, nutrient limitation leads to accumulation of ppGpp (guanosine 3',5'-bisphosphate) [124], which may bind to RNA polymerase [125], where ribosomal RNA and proteins are negatively regulated by ppGpp, which implies that protein biosynthesis declines, and in turn the cell growth rate decreases. During amino acid limitation, (p)ppGpp (including penta-phosphate pppGpp) is mediated by RelA. The accumulation of (p)ppGpp depends on the dual activity of SpoT as (p)ppGpp-hydrolase or ppGpp synthetase. SpoT is activated in response to fatty acid starvation, carbon source starvation, diauxic shifts, phosphate limitation, ion limitation, hyper-osmotic shock, and oxidative stress [126].

The alamone ppGpp is involved in the regulation of $\sigma^{\mathrm{S}}$ on the transcriptional and posttranscriptional level [127]. The elevation of $\sigma^{\mathrm{S}}$ negatively regulates $\sigma^{\mathrm{D}}$-dependent house keeping genes, such as TCA cycle genes [128]. Moreover, ppGpp influences the competition between different stress-related sigma factors in the binding of RNA polymerase core enzyme at the expense of $\sigma^{D}$ [129] and RNA polymerase availability [123].

As implied before, Cra and cAMP-Crp coordinately regulate the main metabolic pathways, and these play important roles for a good economic balance between precursor formation for biosynthesis and energy generation during C-limitation [123]. Catabolite control involves also the regulation of chemotaxis. This indicates that cells pursue "offensive" strategy in order to exploit the low amount of available carbon sources [123]. On the other hand, ppGpp concentration increases with lower growth rates, and affects RpoS, and ppGpp accumulates immediately after onset of nutrient starvation. The nucleotide ppGpp regulates the ribosome concentration and the reduction of the cell growth rate. This might be regarded as "defensive" strategy, because ppGpp thereby regulates the withdrawal of precursors (and energy) from the central carbon metabolism [123].

\section{Stationary Phase Regulation by RpoS}

The culture condition changes from glucose-rich to acetate-rich conditions, and changes further to carbon-starved conditions in the batch cultivation. RpoS, the master regulator of the stationary phase or stress-induced genes regulates such genes as those for the carbohydrate PTS, crr, glycolytic pathway genes such as $f b a B$ and $p f k B$, the acetate-forming gene $p o x B$, the non-oxidative PP pathway genes such as talA and $t k t B$, and TCA cycle genes such as acnA and fumC. In addition, some of the amino acid and fatty acid metabolic pathway genes such as argH, aroM, and $y h g Y$, and energy metabolism genes such as $\operatorname{nar} Y, a p p B$, and $l d c C$ are also regulated in an $r p o S$-dependent manner [130-135]. As the cell utilizes glucose, acetate is produced as the major fermentative product under aerobic condition. Then, the cell utilizes acetate as a carbon source during early stationary phase of growth. When acetate is used up, the cell starts to utilize amino acids as carbon and nitrogen sources during the stationary phase. RpoS regulates the expression of many genes at the onset of stationary phase or carbon-starved conditions as well as other stress conditions in E. coli $[127,133,134]$. RpoS stimulates the expression of several oxidative stress response genes such as $k a t E$, $k a t G$, sodC, and $d p s$ and osmotic stress response genes such as $\operatorname{sim} E$, and $\operatorname{ssm} Y$. Strains lacking a functional rpoS gene also fail to express the genes for acid resistance such as gadA and gadB, near-UV resistance gene $n u v$, acid phosphatase genes appAR [127,131]. 
Under normal situation with roch medium, RpoS is rapidly degraded by ClpXP proteases, and the proteolytic activity of this enzyme is considerably reduced [127,133,134].

Although the roles of RpoS are originally described for various types of stress response, the regulatory roles of RpoS are not restricted to the stress response genes only. In E. coli, RpoS-dependent genes are found all over the chromosome, whose function ranges from DNA repair and protein synthesis to the transport, biosynthesis and metabolism of sugars, amino acids, and fatty acids. RpoS regulates the expression of DNA repair enzymes such as exonuclease encoded by $x$ thA, methyl transferase encoded by $a d a$, the gene that determines the cell morphology such as bolA, the genes encoding transport, and binding proteins such as gabP and ugpEC [132,136]

\section{Biofilm, Motility by Flagella, and Quorum Sensing}

Biofilm formation is one of the important microbial survival strategies, where biofilm development involves attachment of bacteria to surfaces and cell-cell adhesion to form microcolonies. This is useful for the cell to protect against predetors and antibiotics [137]. The attachment of bacteria to abiotic and biotic surfaces is made by motility, proteinaceous adhesion, and a cell-bound polysaccharide such as PGA (poly- $\beta-1,6-\mathrm{N}$-acetyl-D-glucosamine), where PGA is a cell-bound exopolysaccharide adhesion [137]. As mentioned before, Csr plays important roles for biofilm formation, where pga operon is involned in PGA formation and excretion, and it is negatively regulated by CsrA. As mentioned before, CsrA also negatively regulates c-di-GMP, a second messenger involved in biofilm formation and motility [138]. Curli are extracellular proteinaceous structures extending from the cell surface for attachment during biofilm development [139]. Curli filaments are activated by CsgD, where it is inversely correlated with flagella synthesis. The master regulator of flagella synthesis is $\mathrm{FlhD}_{2} \mathrm{C}_{2}$, which activates the genes involved in motility and chemotaxis [140]. McaS (multi-cellular adhesion sRNA) represses CsgD expression, while activates FlhD and PgaA [140], and thus regulates the synthesis of curli flagella and polysaccharide.

As mentioned in the previous section, RpoS plays an important role during the stationary phase. The csrA expression is also under control of RpoS [141]. Moreover, biofilm formation is under catabolite repression by cAMP and Crp [142].

Quorum sensing is a cell-to-cell communication [143], where the signal molecules are homoserine lactones (AHL) synthesized by LuxI-type enzyme. At high cell density cultivations, LuxR-type regulator plays a role for the positive feedback in association with AHL when its concentration exceeds a threshold level [8]. The quorum sensing is considered to be the sensing of cell density, where in E.coli, CyaR represses luxS gene which encodes autoinducer-2 synthase [11].

\section{Death Phase and Long-Term Stationary Phase Metabolism}

After the stationary phase in the batch culture, the death phase and long-term stationary phase follow [144]. During the stationary phase, nutrient becomes exhausted, and waste products gradually accumulate, which may become a stress to the cell, and this eventually leads to the death phase in which the number of viable and culturable cells declines. Since the majority of the cells in the death phase are viable but non-cultuable or die, nutrients from a portion of such cells are released into the medium. The released nutrients support the survival of the remaining culturable cells, and viable and 
culturable cells can survive for months or years in the long-term stationary phase $[145,146]$. The $\sigma^{\mathrm{E}}$-dependent cell lysis is to eliminate damaged cells in the stationary phase in E.coli [146], where the cell lysis proceeds in the cascade of $\sigma^{\mathrm{E}} \rightarrow$ expression of mic $A$ and $r y b B \rightarrow$ reduction in Omp proteins in the outer membrane $\rightarrow$ disintegration of outer membrane [147]. The cell lysis cascade appears to be related to oxidative stress in the early stationary phase [148].

\section{Effect of Oxidative Stress on the Metabolism}

The microbial cell responds to oxidative stress by inducing antioxidant proteins such as superoxide dismutase (SOD) and catalase, where those are regulated by OxyR and SoxR [149]. SoxR is a member of the MerR family of metal-binding transcription factors, and it exists in solution as a homodimer with each subunit containing a [2Fe-2S] cluster. These clusters are in the reduced state in inactivated SoxR, and their oxidation activates SoxR as a powerful transcription factor [150]. The active form of SoxR activates transcription of sox gene, and its product, SoxS, belongs to the AraC/XylS family of DNA-binding transcription factors. Oxygen derivatives such as superoxide $\left(\mathrm{O}_{2}{ }^{-}\right)$, hydrogenperoxide $\left(\mathrm{H}_{2} \mathrm{O}_{2}\right)$, and the hydroxyl radical $(\mathrm{OH})$ are usually generated as toxic by-products of aerobic metabolism in a cascade of monovalent reductions from molecular oxygen. Although these are not so reactive per se, $\mathrm{O}^{-}$and $\mathrm{H}_{2} \mathrm{O}_{2}$ cause severe cell damage. $\mathrm{H}_{2} \mathrm{O}_{2}$ along with $\mathrm{Fe}^{2+}$ via the Fenton reaction produces $\mathrm{OH}$, which reacts with any macromolecule such as protein, membrane constituents, and DNA [151,152]. $\mathrm{O}_{2}{ }^{-}$exacerbates the Fenton reaction by increasing the intracellular pool of free iron, for instance, by releasing iron from $\mathrm{O}_{2}^{-}$-oxidized [4Fe-4S] clusters. Despite their toxicity, reactive oxygen species (ROS) at low concentration are involved in the cell's life and, therefore, should not be entirely eliminated. Potent basic defense systems maintain ROS at harmless levels but cannot deal with sudden increases in ROS production as oxidative stress.

The two enzymes involved in the oxidative PP pathway, G6PDH and 6PGDH that produce NADPH for biosynthesis, are significantly affected in both $\operatorname{sox} R$ and $\operatorname{sox} S$ mutants [153]. The activities of G6PDH and 6PGDH decrease in soxR and soxS mutants, compared to the parent stain. The down regulations of these two enzymes agree with slower growth rates in both mutants, since these enzymes are under growth rate-dependent regulation [154]. The down regulation of $z w f$ gene in both mutants is also due to the effects of $\operatorname{sox} S$ and $\operatorname{sox} R$ genes deletion, since $z w f$ is a member of soxRS and multiple antibiotic resistance (mar) regulons. Unlike gnd, $z w f$ expression is transcriptionally activated by SoxS for oxidative stress [152,155] (Supplementary Figure S1). The pntA (membrane bound transhydrogenase) transcripts which is involved in NADPH generation from NADH [156], are up-regulated in both soxR and soxS mutants to backup the reduced NADPH production in these mutants, since NADPH plays a significant role to reduce oxidative stress [156].

As the specific glucose consumption rate increases, and the respiration increases, SoxR/S is activated as implied in Figure $4 \mathrm{a}$. Then, SoxS activates $z w f$ gene expression (Figure 4d), where the activation of the oxidative PP pathways may be due to NADPH production for oxidative stress as well as for the cell synthesis (Figure 6). 
Figure 6. (a) Oxidative stress in the respiration; and (b)metabolic regulation for NADPH production.

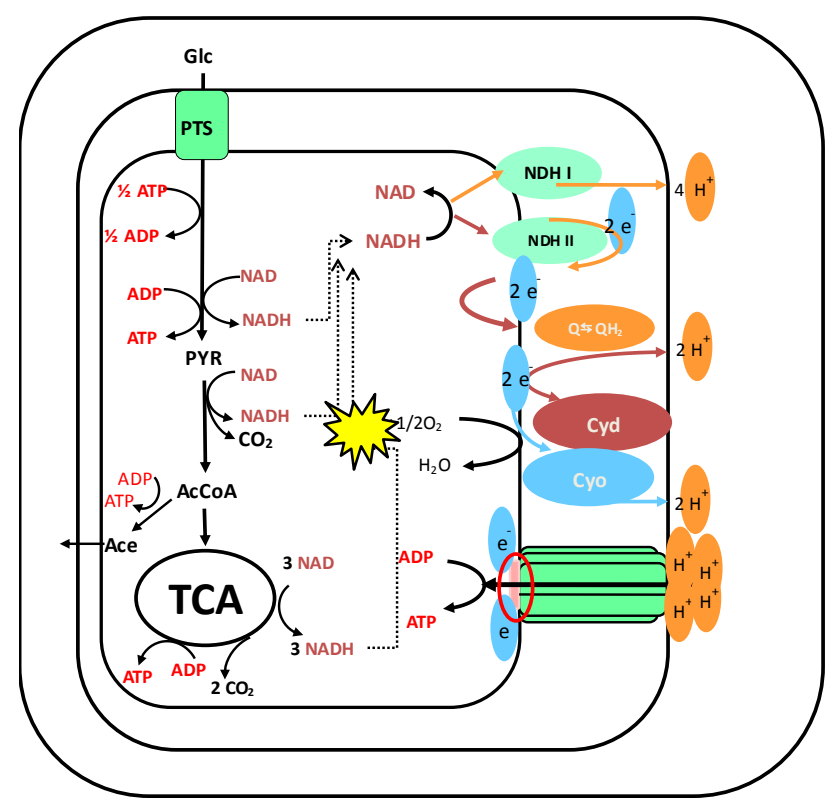

(a)

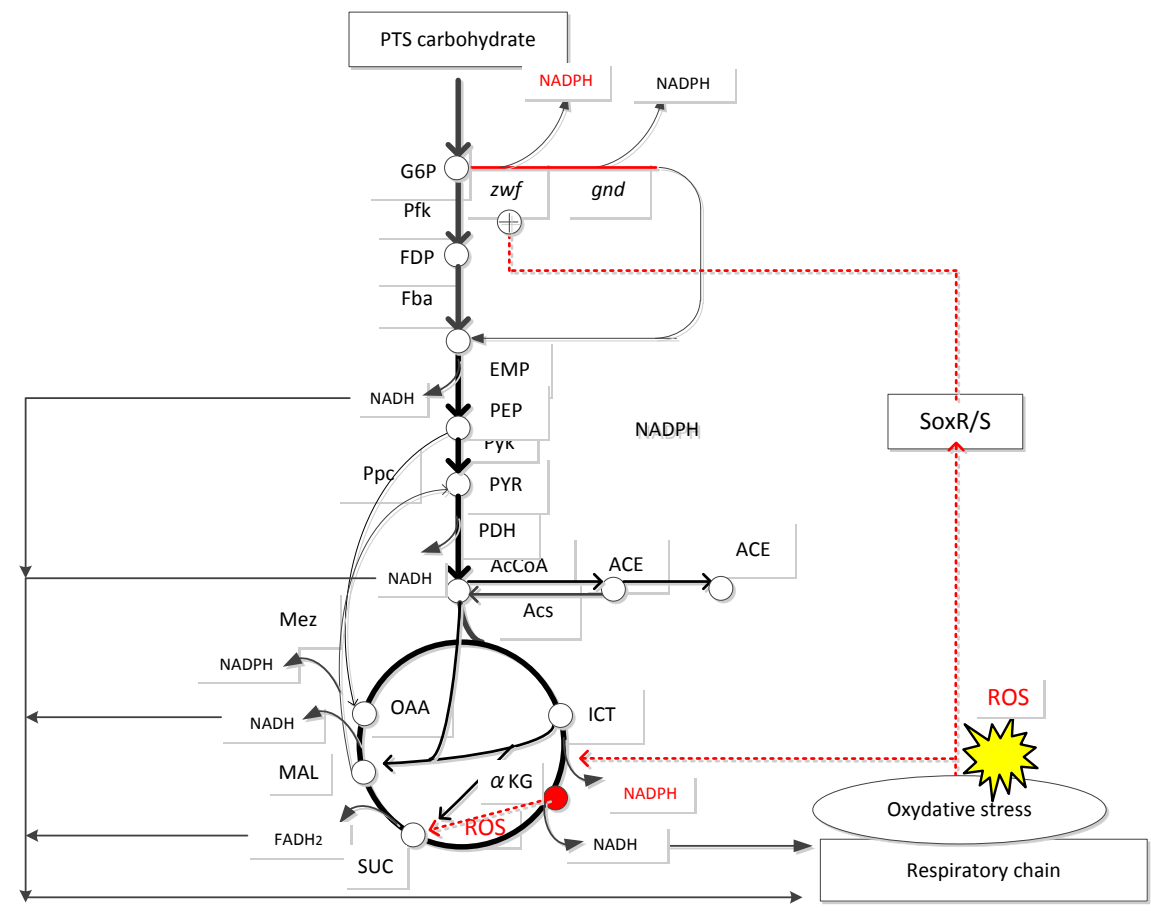

(b)

In general, all aerobic organisms produce NADH and $\mathrm{FADH}_{2}$ in the TCA cycle, where these reducing equivalents are oxidized in the respiratory chain, and the electrons generated from the reducing equivalents are subsequently transferred to cytochromes where $\mathrm{O}_{2}$ is converted to $\mathrm{H}_{2} \mathrm{O}$. The ATP is then generated by the proton motive force (PMF) with ATPase (Figure 6a). Although this process is universal among all aerobic organisms, inefficient electron transfer via the respiratory complexes results in one electron reduction of diatomic oxygen, a phenomenon known to generate toxic ROS [157]. Since NADPH plays an important role for detoxification of ROS, some prokaryotic microorganisms such as E.coli produce NADPH at ICDH in the TCA cycle together with the reactions 
at G6PDH, 6PGDH, and possibly at Mez (Figure 6b). As the oxygen level decreases with reduced activity of the TCA cycle, less ROS is generated, and the NAD $(\mathrm{P}) \mathrm{H}$ generated at ICDH varies in general [157].

$\alpha \mathrm{KG}$ is a key participant in the detoxification of ROS such as $\mathrm{H}_{2} \mathrm{O}_{2}$ and $\mathrm{O}_{2}{ }^{-}$with concomitant formation of succinate, where it is a biomarker for oxidative stress [157] (Figure 6b). Moreover, NADPH producing ICDH is activated, while NADH producing KGDH is deactivated in the cultivation of Pseudomonas fluorescens [157]. This indicates that for both prokaryotic and eukaryotic cells, the TCA cycle acts both as a scavenger and generator of ROS, and its modulation is important for regulating intracellular ROS (Figure 6b). Note that, unlike ROS detoxifying agents such as SOD and catalase, which only decompose ROS without affecting their production [158], the TCA cycle can regulate both their formation and decomposition. The concomitant accumulation of succinate may act as a potent signal for this [159] (Figure 6b).

\section{Acid Shock Response}

The cell such as E.coli has the regulation systems in response to acidic condition [159-162]. Some of these depend on the available extracellular amino acids such as glutamate, arginine, and lysine, where the intracellular proton is consumed by the reductive decarboxylation of the amino acid followed by the excretion of $\gamma$-amino butyric acid (GABA) from cytoplasm to the periplasm by the anti-porter that also imports the original amino acid [159]. E. coli is acid resistant by such genes as gad $A B$ which encodes glutamate decarboxylase and gadC which encodes glutamate/GABA anti-porter. Glutamate decarboxylase production increases in response to acid, osmotic, and stationary phase signals. The gadA and gadB genes for glutamate decarboxylase isozymes form a glutamate-dependent acid response system, where the process of decarboxylation consumes an intracellular proton and helps maintain $\mathrm{pH}$ homeostasis. There exists similar acid resistant systems for the case of using arginine instead of glutamate by arginine decarboxylase, where the antiporter is AdiC in this case [163,164], and for the case of using lysine by lysine decarboxylase [164]. The cells grown in media rich with amino acids such as LB are acid resistant [159].

In the typical batch culture, organic acids are mostly accumulated at the late growth phase or the stationary phase, and GadA and GadB proteins increase in response to the stationary phase and at low $\mathrm{pH}$ [165]. RpoS, which increases at the late growth phase and the stationary phase as well as Crp, is involved in acid resistance [159]. As implied by the involvement of Crp, the acid resistant system is repressed when glucose is present. Moreover, ATPase is involved in this system [162], where ATPase is mainly utilized for the protons in the periplasm move into the cytosol across the cell membrane producing ATP from ADP and $\mathrm{P}_{\mathrm{i}}$ by the negative proton motive force (PMF). Since the basic problem of acid stress is the accumulated proton in the cytosol, this proton may be pumped out through ATPase by hydrolyzing ATP with reversed proton move due to positive PMF at low $\mathrm{pH}$ such as $\mathrm{pH} 2$ or 3 [162]. Without amino acid in the media, this acid response system is activated by utilizing ATPase $[161,166]$, where the positive PMF pumps extra protons $\left(\mathrm{H}^{+}\right)$from the cytoplasm with consumption of ATP [162]. Namely, PMF is operated in the reverse direction as compared to the case of producing ATP.

The acidic $\mathrm{pH}$ lowers cAMP levels in exponentially growing cells in the minimal glucose medium. Since cAMP-Crp represses RpoS, this may elevate RpoS, and increases the expression of gadX. 
However, GadW represses RpoS synthesis at acidic condition, and in turn GadX synthesis. GadX, when not repressed by GadW, is acid induced due to changes in cAMP. GadW is also acid-induced when it is not repressed by GadX. GadX directly binds to the gadW promoter region. The overall regulation system seems to be quite complex, involving EvgS/A, B1500, PhoQ/PhoP [167].

As explained before, the two-component system of EnvZ and OmpR regulates porin expression, where OmpR may be a key regulator for acid adaptation, and thus ompR mutant is sensitive to acid exposure [152]. The acid-inducible $a s r$ gene is regulated by the two-component system $\mathrm{PhoR} / \mathrm{B}$, and thus $p h o R / p h o B$ deletion mutant fails to induce asr gene expression [168].

\section{Heat Shock Response}

The organisms respond to a sudden temperature up-shift by increasing the synthesis of a set of proteins. This phenomenon is called as heat shock response, where this does not restrict to the temperature up-shift, but also other stresses, as will be mentioned later in the section of solvent stress. The heat shock proteins play important roles in the assembly and disassembly of macromolecular complex such as GroE, the intracellular transport such as Hsp70, transcription such as $\sigma^{70}$, proteolysis such as Lon, and translation such as lysyl tRNA synthetase. The heat shock response in E. coli is mediated by $\mathrm{E \sigma}^{32}$, where $\mathrm{E}$ denotes RNA polymerase holoenzyme. Among them, groEL, dnaK, and $h t p G$ encode major chaperones such as Hsp 60, Hsp 70, and Hsp 90. ClpP, Lon, and HtrC are involved in the proteolysis. DnaK, DnaJ, GrpE, and RpoH are involved in the autoregulation of heat shock response. DnaK prevents the formation of inclusion bodies by reducing aggregation and promotion of proteolysis of misfolded proteins. A bichaperone system involving DnaK and ClpB mediates the solubilization or disaggregation of proteins. GroEL operates protein transit between soluble and insoluble protein fractions and participates positively in disaggregation and inclusion body formation. Small heat shock proteins such as $\mathrm{IbpA}$ and $\mathrm{IbpB}$ protect heat-denatured proteins from irreversible changes in association with inclusion bodies $[169,170]$.

Hoffmann et al. [171] investigated the metabolic adaptation of E. coli during temperature induced recombinant protein production, and showed that cAMP/Crp- controlled LpdA of pyruvate dehydrogenase complex (PDHc) and SdhA in the TCA cycle are highly induced. In E. coli, heat shock protein synthesis rates peak at about 5-10 min after the temperature upshift and then decline to a new steady-state level [172]. $\sigma^{70}$ is itself a heat shock protein, and the increase in its concentration after heat shock may contribute to its decline in heat shock protein synthesis. DnaK contributes to the shutoff of the high level synthesis of heat shock proteins [173].

Upon heat shock, crp gene expression increases, and $\operatorname{lp} d A$ gene expression follows the similar pattern. Moreover, $m l c$ gene expression follows the similar pattern as that of $r p o H$. E $\sigma^{32}$ plays an important role in balancing the relative concentration of Mlc and EIICB in response to the availability of glucose in order to maintain inducibility of Mlc regulon at higher temperature [174]. The mlc gene is transcribed by two promoters, $\mathrm{P}_{1}$ and $\mathrm{P}_{2}$, and has a binding site of its own gene product, where $\mathrm{P}_{2}$ promoter could be recognized by RNA polymerase containing the heat shock sigma factor.

Let us consider the production mechanism of acetate at higher temperature. Acetate excretion occurs through Pta-Ack pathway, or may possibly by Pox pathway. Acetate utilization occurs through Acs. Transcription occurs from two $\sigma^{70}$-dependent promoters such as distal promoter acs $\mathrm{P}_{1}$ and 
proximal promoter acs $\mathrm{P}_{2}[175,176]$. Crp functions directly as the critical transcription factor. Cells control the acetate switch primarily by controlling the initiation of acs transcription from the major promoter acs $\mathrm{P}_{2}$ [175,177]. Activation of acs transcription depends on cAMP-Crp (Supplementary Figure S1). The cAMP-Crp binds two sites within the acs regulatory region. However, Fis and Ihf independently modulate Crp-dependent activation of acs $\mathrm{P}_{2}$ transcription [178]. As such, the activation of crp may cause acs to be upregulated, where acs gene is also under control of RpoS [179].

The respiration is activated during the temperature upshift [171], and superoxide dismutase gene (sod) is induced in response to the oxidative stress imposed by dioxygen or by the redox active compounds such as viologens or quinones caused by the temperature up-shift [180].

\section{Tolerance to Various Stresses in Biofuels Production by Microorganisms}

The biofuels production by microorganisms has been paid recent attention. However, many biofuels are toxic to microorganisms, and reduce the cell viability through damage to the cell membrane and interference with essential physiological processes. Several attempts have been made to improve the tolerance to biofuels, where biofuel export systems, heat shock proteins, and membrane modifications have been considered [181]. The effect of biofuels on the cell is through hydrophobicity of the cytoplasmic membrane, where the accumulation of solvent in the cytoplamic membrane increases permeability of membrane, diminishes energy transduction, interferes with membrane protein function, and increases fluidity [181-184]. This may cause the release of ATP, ions, and phospholipids, RNA and proteins, and thus the cell growth is depressed due to disturbances on ATP production by diminished proton motive force (PMF). Moreover, the increase in fluidity affects the nutrient transport as well as energy transduction.

Toxicity levels vary depending on the microbes and the types of biofuels and biochemicals. In general, longer chain alcohols are more toxic than short chain alcohols. Efflux pumps are membrane transporters that recognize and export toxic compounds from the cell by PMF, where this is important for the cell to survive by exporting bile salts, antimicrobial drugs, and solvents. The acrAB-tolC pump in E.coli provides tolerance to hexane, heptanes, octane, and nonane [185]. Efflux pumps are effective for increasing tolerance and production of biofuels, in particular, for long chain alcohols such as alkanes, alkenes, and cyclic hydrocarbons, but those are not effective for exporting short chain alcohols such as 1-propanol and isobutanol [186].

The heat shock proteins are up-regulated in response to short chain alcohols [187], where the sigma factor for heat shock such as $\mathrm{RpoH}$ is activated [110], and heat shock and protein refolding genes such as $r p o H, d n a J, h t p G$, and $i b p A B$ are up-regulated [188], while groESL, dnaKJ, hsp18, hsp90 are p-regulated in Chrostridium acetobutylicum [189]. Over-expression of heat shock proteins may increase tolerance against biofuels [190,191].

In general, solvents disrupt the cell membrane structure and have a strong impact on physiological function, and eventually leading to the cell death [192]. To overcome this problem, solvent tolerant microbes change the composition of the fatty acids from cis to trans unsaturated fatty acids catalyzed by cis-trans isomerase (cti), thus decreasing membrane fluidity, preventing the entry of solvents into the cell $[193,194]$. In addition, modifications to phospholipid headgroups or phospholipid chain length increase solvent tolerance [187]. 
In relation to solvent stresses caused by the accumulation of biofuels in the culture broth, the primary role to protect the cell from such stress is made by outer membrane porin proteins. Since cytosolic membrane is also under stress condition, respiration and membrane proteins as well as general stress response mechanism are affected [184]. Several transcription factors are affected by isobutanol in E.coli [110]. The reactive oxygen species (ROS) highly increase in response to the stress caused by n-butanol in E.coli [188]. Moreover, the improved tolerance against n-butanol can be made by over-expression of ion transport and metabolism genes such as entC and $f e o A$, as well as acid resistance-related gene $a s t E$ and inner membrane protein gene ygiH [191].

In order to keep $\mathrm{pH}$ constant, alkali such as $\mathrm{NaOH}$ is supplied during the cell growth in practice, which results in the increase in sodium ion $\left(\mathrm{Na}^{+}\right)$, where nhaA gene encoding $\mathrm{Na}^{+} / \mathrm{H}^{+}$antiporter membrane protein and $n h a R$ gene encoding the NhaA regulatory protein can be overexpressed in $p f l B$ mutant, showing performance improvement for lactate fermentation [195].

RpoS plays important roles in response to the stresses caused by the accumulation of biofuels $[110,196]$. Some of the global regulators such as ArcA, Fur, and PhoB are activated, probably indirectly, by isobutanol [110].

\section{Concluding Remarks}

As seen above, the global regulators are responsive to the specific stimuli. Examples of such pleiotropic TFs in E.coli are Crp, a primary sensor for C-availability, NtrBC, a sensor for $\mathrm{N}$-availability, PstSCAB and PhoR, the sensor for P-availability, CysB, the sensor for S-availability, and Fur, the sensor for ion availability. Functional interactions among such regulators must coordinate the activities of the metabolon so that the supply of one type of nutrient matches the supply of other nutrients [197]. Thus, multiple links between $\mathrm{C}$ and $\mathrm{N}$ metabolism has been identified [77,198]. Other functional links between $\mathrm{C}$ and $\mathrm{S}$ metabolism [199], and between $\mathrm{C}$ and ion metabolism [116,200] have been identified. Moreover, the links between $\mathrm{S}$ and $\mathrm{N}$ limitations are also identified [90].

In general, bacteria in nature live far away from the optimal growth conditions, where multiple stresses are imposed to the cell. Therefore, the cell must have the ability to sense, integrate, and respond to a variety of stresses for survival. Although little is known about "cross-stress" protection, cross stress dependencies are ubiquitous, highly interconnected, and may emerge within short time frames [201]. In E.coli, pre-adaptation to $\mathrm{C}$ or $\mathrm{N}$ limitation increases survival rates after heat shock or oxidative stress [202], where a possible link may be made by a heat shock regulator, RpoH [203]. Crp may play some role in this, since it is commonly involved in the above stresses. In fact, a high degree of overlap was observed in the transcriptional profiling for different stresses such as starvation, osmotic and acidic stresses [136], where high osmolarity and high temperature induces the oxidative stress regulons such as SoxRS and OxyR [204,205]. The responses to n-butanol share the same high overlap with those in heat shock, oxidative, and acidic stresses [188].

As mentioned in this article, the specific metabolites such as FDP, PEP, PYR, and $\alpha \mathrm{KG}$ in the main metabolic pathways play important roles for metabolic regulation. This implies that these metabolites might play roles for the coordinated and integrated metabolic regulation. Note, however, that metabolomics alone is inadequate to understand cellular metabolic activity [206]. It is quite important to correctly understand the metabolic regulation in response to nutrient starvation and culture 
environmental stresses by integrating different levels of information such as fluxes, protein expression, gene expression as well as metabolite concentrations. What we understand the metabolic regulation mechanism so far is limited, and it may be important to get deep insight into the whole cellular metabolic systems, and apply this for the next generation metabolic engineering.

\section{Conflicts of Interest}

The authors declare no conflict of interest.

\section{References}

1. Seshasayee, A.S.; Bertone, P.; Fraser, G.M.; Luscombe, N.M. Transcriptional regulatory networks in bacteria: From input signals to output responses. Curr. Opin. Microbiol. 2006, 9 , 511-519.

2. Kitano, H. Systems biology: A brief overview. Science 2002, 295, 1662-1664.

3. Kitano, H. Computational systems biology. Nature 2002, 420, 206-210.

4. Kotte, O.; Zaugg, J.B.; Heinemann, M. Bacterial adaptation through distributed sensing of metabolic fluxes. Mol. Syst. Biol. 2010, 6, 355.

5. Kanehisa, M.; Goto, S.; Hattori, M.; Aoki-Kinoshita, K.F.; Itoh, M.; Kawashima, S.; Katayama, T.; Araki, M.; Hirakawa, M. From genomics to chemical genomics: New developments in KEGG. Nucleic Acids Res. 2006, 34, D354-D357.

6. Yamamoto, K.; Hirao, K.; Oshima, T.; Aiba, H.; Utsumi, R.; Ishihama, A. Functional characterization in vitro of all two component signal transduction systems from Escherichia coli. J. Biol. Chem. 2005, 280, 1448-1456.

7. Maeda, H.; Fujita, N.; Ishihama, A. Competition among seven Escherichia coli sigma subunits: Relative binding affi nities to the core RNA polymerase. Nucleic Acids Res. 2000, 28, 3497-3503.

8. Timmermans, J.; van Melderen, L. Post-transcriptional global regulation by CsrA in bacteria. Cell. Mol. Life Sci. 2010, 67, 2897-2908.

9. Bruckner, R.; Titgemeyer, F. Carbon catabolite repression in bacteria: Choice of the carbon source and autoregulatory limitation of sugar utilization. FEMS Microbiol. Lett. 2002, 209, $141-148$.

10. Gutierrez-RiosR, M.; Freyre-Gonzalez, J.A.; Resendis, O.; Collado-Vides, J.; Saier, M.; Gosset, G. Identification of regulatory network topological units coordinating the genome-wide transcriptional response to glucose in Escherichia coli. BMC Microbiol. 2007, 7, 53.

11. De Lay, N.; Gottesman, S. The crp-activated small noncoding regulatory RNA CyaR (RyeE) links nutritional status to group behavior. J. Bacteriol. 2009, 191, 461-476.

12. Muller, C.M.; Aberg, A.; Straseviciene, J.; Emody, L.; Uhlin, B.E.; Balsalobre, C. Type 1 fimbriae, a colonization factor of uropathogenic Escherichia coli, are controlled by the metabolic sensor CRP-cAMP. PLoS Pathog. 2009, 5, e1000303.

13. Zheng, D.; Constantinidou, C.; Hobman, J.L.; Minchin, S.D. Identification of the CRP regulon using in vitro and in vivo transcriptional profiling. Nucleic Acids Res. 2004, 32, 5874-5893.

14. Gottesman, S. Micros for microbes: Non-coding regulatory RNAs in bacteria. Trends Genet. 2005, 21, 399-404. 
15. Vanderpool, C.K.; Gottesman, S. Involvement of a novel transcriptional activator and smallRNA in post-transcriptional regulation of the glucose phosphoenolpyruvate phosphotransferase system. Mol. Microbiol. 2004, 54, 1076-1089.

16. Babitzke, P.; Romeo, T. CsrB sRNA family: Sequestration of RNA-binding regulatory proteins. Curr. Opin. Microbiol. 2007, 10, 156-163.

17. Sauer, E.; Weichenrieder, O. Structural basis for RNA 3'-end recognition by Hfq. Proc. Natl. Acad. Sci. USA 2011, 108, 13065-13070.

18. Sauer, E.; Schmidt, S.; Weichenrieder, O. Small RNA binding to the lateral surface of Hfa hexamers and structural rearrangements upon mRNA target recognition. Proc. Natl. Acad. Sci. USA 2012, 109, 9396-9401.

19. Voge, J.; Luis, B.F. Hfq and its constellation of RNA. Nat. Rev. Microbiol. 2011, 9, 578-589.

20. Shimizu, K. Bacterial Cellular Metabolic Systems; Woodhead Publ. Co.: Oxford, UK, 2013.

21. Shimizu, K. Metabolic regulation of a bacterial cell system with emphasis on Escherichia coli metabolism. ISRN Biochem. 2013, 645983:1-645983:47.

22. Simon, S.A.; Gutknecht, J. Solubility of carbon dioxide in lipid bilayer membranes and organic solvents. Biochim. Biophys. Acta 1980, 596, 352-358.

23. Walter, A.; Gutknecht, J. Permeability of small nonelectrolytes through lipid bilayer membranes. J. Membr. Biol. 1986, 90, 207-217.

24. Nikaido, H.; Nakae, T. The outer membrane of gram-negative bacteria. Adv. Microb. Physiol. 1980, 20, 163-250.

25. De la Cruz, M.A.; Fernandez-Mora, M.; Guadarrama, C.; Flores-Valdez, M.A.; Bustamante, V.H.; Vázquez, A.; Calva, E. LeuO antagonizes H-NS and StpA-dependent repression in Salmonella enterica ompS1. Mol. Microbiol. 2007, 66, 727-743.

26. Nikaido, H. Molecular basis of bacterial outer membrane permeability revisited. Microbiol. Mol. Biol. Rev. 2003, 67, 593-656.

27. Nikaido, H. Outer Membrane; Neidhardt, F.C., Ed.; ASM Press: Washington, DC, USA, 1996.

28. Death, A.; Ferenci, T. Between feast and famine: Endogenous inducer synthesis in the adaptation of Escherichia coli to growth with limiting carbohydrates. J. Bacteriol. 1994, 176, 5101-5107.

29. Von Meyenburg, K.; Nikaido, H. Outer membrane of gramnegative bacteria. XVII. Specificity of transport process catalyzed by the $\lambda$-receptor protein in Escherichia coli. Biochem. Biophys. Res. Commun. 1977, 78, 1100-1107.

30. Brzostek, K.; Brzostkowska, M.; Bukowska, I.; Karwicka, E.; Raczkowska, A. OmpR negatively regulates expression of invasion in Yersinia enterocolitica. Microbiology 2007, 153, 2416-2425.

31. Gunnewijk, M.G.W.; van den Bogaard, P.T.C.; Veenhoff, L.M.; Heuberger, E.H.; de Vos, W.M.; Kleerebezem, M.; Kuipers, O.P.; Poolman, B. Hierarchical control versus autoregulation of carbohydrate utilization in bacteria. J. Mol. Microbiol. Biotechnol. 2001, 3, 401-413.

32. Postma, P.W.; Lengeler, J.W.; Jacobson, G.R. Phosphoenolpyruvate: Carbohydrate Phosphotransferase Systems. In Escherichia coli and Salmonella: Cellular and Molecular Biology; Neidhardt, F.C., Ed.; ASM Press: Washington, DC, USA, 1996; pp. 1149-1174.

33. Tchieu, J.H.; Norris, V.; Edwards, J.S.; Saier, M.H., Jr. The complete phosphotransferase system in Escherichia coli. J. Mol. Microbiol. Biotechnol. 2001, 3, 329-346. 
34. Chou, C.H.; Bennett, G.N.; San, K.Y. Effect ofmodulated glucose uptake on high-level recombinant protein production in a dense Escherichia coli culture. Biotechnol. Prog. 1994, 10, 644-647.

35. Gosset, G. Improvement of Escherichia coli production strains by modification of the phosphoenolpyruvate: Sugar phosphotransferase system. Microb. Cell Fact. 2005, 4, 14.

36. Lunin, V.V.; Li, Y.; Schrag, J.D.; Iannuzzi, P.; Cygler, M.; Matte, A. Crystal structures of Escherichia coli ATP-dependent glucokinase and its complex with glucose. J. Bacteriol. 2004, 186, 6915-6927.

37. Huberts, D.H.; Niebel, B.; Heinemann, M. A flux-sensing mechanism could regulate the switch between respiration and fermentation. FEMS Yeast Res. 2012, 12, 118-128.

38. Kochanowski, K.; Volkmer, B.; Gerosa, L.; van Rijsewijk, H.B.R.; Schmidt, A.; Heinemann, M. Functioning of a metabolic flux sensor in Escherichia coli. Proc. Natl. Acad. Sci. USA 2013, 110, 1130-1135.

39. Valgepea, K.; Adamberg, K.; Nahku, R.; Lahtvee, P.J.; Arike, L.; Vilu, R. Systems biology approach reveals that overflow metabolism of acetate in Escherichia coli is triggered by carbon catabolite repression of acetyl-CoA synthetase. BMC Syst. Biol. 2010, 4, 166.

40. Valgepea, K.; Adamberg, K.; Vilu, R. Decrease of energy spilling in Escherichia coli continuous cultures with rising specific growth rate and carbon wasting. BMC Syst. Biol. 2011, 5, 106.

41. Kayser, A.; Weber, J.; Hecht, V.; Rinas, U. Metabolic flux analysis of Escherichia coli in glucose-limited continuous culture. I. Growth-rate dependent metabolic efficiency at steady state. Microbiology 2005, 151, 693-706.

42. Nachen, A.; Schicker, A.; Revelles, O.; Sauer, U. Cyclic AMP-dependent catabolite repression is the dominant control mechanism of metabolic fluxes under glucose limitation in Escherichia coli. J. Biotechnol. 2008, 190, 2323-2330.

43. Hua, Q.; Yang, C.; Baba, T.; Mori, H.; Shimizu, K. Responses of the central carbon metabolism in Escherichia coli to phosphoglucose isomerase and glucose-6-phosphate dehydrogenase knockouts. J. Bacteriol. 2003, 185, 7053-7067.

44. Bettenbrock, K.; Sauter, T.; Jahreis, K.; Klemling, A.; Lengeler, J.W.; Gilles, E.D. Correlation be-tween growth rates, EIIACrr phosphorylation, and intra-cellular cyclic AMP levels in Escherichia coli K-12. J. Bacteriol. 2007, 189, 6891-6900.

45. Hogema, B.M.; Arents, J.C.; Bader, R.; Eijkemans, K.; Yoshida, H.; Takahashi, H.; Aiba, H.; Postma, P.W. Inducer exclusion in Escherichia coli by non-PTS substrates: The role of the PEP to pyruvate ratio in deter-mining the phosphorylation state of enzyme IIAGlc. Mol. Microbiol. 1998, 30, 487-498.

46. Matsuoka, Y.; Shimizu, K. Catabolite regulation analysis of Escherichia coli for acetate overflow mechanism and co-consumption of multiple sugars based on systems biology approach using computer simulation. J. Biotechnol. 2013, 168, 155-173.

47. Yao, R.; Hirose, Y.; Sarkar, D.; Nakahigashi, K.; Ye, Q.; Shimizu, K. Catabolic regulation analysis of Escherichia coli and its crp, mlc, mgsA, pgi and ptsG mutants. Microb. Cell Fact. 2011, 10, 67. 
48. Ishii, N.; Nakahigashi, K.; Baba, T.; Robert, M.; Soga, T.; Kanai, A.; Hirasawa, T.; Naba, M.; Hirai, K.; Hoque, A.; et al. Multiple high-throughput analyses monitor the response of E. coli to perturbations. Science 2007, 316, 593-597.

49. Brauer, M.J.; Yuan, J.; Bennett, B.D.; Lu, W.; Kimball, E.; Botstein, D.; Rabinowitz, J.D. Conservation of the metabolomic response to starvation across two divergent microbes. Proc. Natl. Acad. Sci. USA 2006, 103, 19302-19307.

50. Zampar, G.G.; Kümmel, A.; Ewald, J.; Jol, S.; Niebel, B.; Picotti, P.; Aebersold, R.; Sauer, U.; Zamboni, N.; Heinemann, M. Temporal system-level organization of the switch from glycolytic to gluconeogenic operation in yeast. Mol. Syst. Biol. 2013, 9, 651.

51. Romeo, T. Global regulation by the small RNA-binding protein CsrA and the non- coding RNA molecule CsrB. Mol. Microbiol. 1998, 29, 1321-1330.

52. Jonas, K.; Edwards, A.N.; Ahmad, I.; Romeo, T.; Romling, U.; Melefors, O. Complex regulatory network encompassing the Csr, c-di-GMP and motility systems of Salmonella typhimurium. Environ. Microbiol. 2010, 12, 524-540.

53. Yakhnin, H.; Pandit, P.; Petty, T.J.; Baker, C.S.; Romeo, T.; Babitzke, P. CsrA of Bacillus subtilis regulates translation initiation of the gene encoding the flagellin protein (hag) by blocking ribosome binding. Mol. Microbiol. 2007, 64, 1605-1620.

54. Romeo, T.; Gong, M. Genetic and physical mapping of the regulatory gene csrA on the Escherichia coli K-12 chromosome. J. Bacteriol. 1993, 175, 5740-5741.

55. Romeo, T.; Gong, M.; Liu, M.Y.; Brun-Zinkernagel, A.M. Identification and molecular characterization of $\operatorname{csr} A$, a pleiotropic gene from Escherichia coli that affects glycogen biosynthesis, gluconeogenesis, cell size, and surface properties. J. Bacteriol. 1993, 175, 4744-4755.

56. Romeo, T. Post-transcriptional regulation of bacterial carbohydratemetabolism: Evidence that the gene productCsrA is global mRNA decay factor. Res. Microbiol. 1996,147, 505-512.

57. Dubey, A.K.; Baker, C.S.; Romeo, T.; Babitzke, P. RNA sequence and secondary structure participate in high-affinity CsrA-RNA interaction. RNA 2005, 11, 1579-1587.

58. Suzuki, K.; Wang, X.; Weilbacher, T.; Pernestig, A.K.; Melefors, O.; Georgellis, D.; Babitzke, P.; Romeo, T. Regulatory circuitry of the CsrA/CsrB and BarA/UvrY systems of Escherichia coli. J. Bacteriol. 2002, 184, 5130-5140.

59. Weilbacher, T.; Suzuki, K.; Dubey, A.K.; Wang, X.; Gudapaty, S.; Morozov, I.; Baker, C.S.; Georgellis, D.; Babitzke, P.; Romeo, T. A novel sRNA component of the carbon storage regulatory system of Escherichia coli. Mol. Microbiol. 2003, 48, 657-670.

60. Baker, C.S.; Morozov, I.; Suzuki, K.; Romeo, T.; Babitzke, P. CsrA regulates glycogen biosynthesis by preventing translation of $g \operatorname{lgC}$ in Escherichia coli. Mol. Microbiol. 2002, 44, 1599-1610.

61. McKee, A.E.; Rutherford, B.J.; Chivian, D.C.; Baidoo, E.K.; Juminaga, D.; Kuo, D.; Benke, P.I.; Dietrich, J.A.; Ma, S.M.; Arkin, A.P.; et al. Manipulation of the carbon storage regulator system for metabolite remodeling and biofuel production in Escherichia coli. Microb. Cell Fact. 2012, 11,79 .

62. Tatarko, M.; Romeo, T. Disruption of a global regulatory gene to enhance CEntral carbon flux into Phenylalanine biosynthesis in Escherichia coli. Curr. Microbiol. 2001, 43, 26-32. 
63. Edwards, A.N.; Patterson-Fortin, L.M.; Vakulskas, C.A.; Mercante, J.W.; Potrykus, K.; Vinella, D.; Camacho, M.I.; Fields, J.A.; Thompson, S.A.; Georgellis, D.; et al. Circuitry linking the Csr and stringent response global regulatory systems. Mol. Microbiol. 2011, 80, 1561-1580.

64. Yan, D. Protection of the glutamate pool concentration in enteric bacteria. Proc. Natl. Acad. Sci. USA 2007, 104, 9475-9480.

65. Ninfa, A.J.; Jiang, P.; Atkinson, M.R.; Peliska, J.A. Integration of antagonistic signals in the regulation of nitrogen assimilation in Escherichia coli. Curr. Topics Cell. Regul. 2000, 36, 31-75.

66. Gruswitz, F.; O’Connell, J.; Stroud, R.M. Inhibitory complex of the transmembrane ammonia channel, AmtB, and the cytosolic regulatory protein, GlnK, at 1.96 A. Proc. Natl. Acad. Sci. USA 2007, 104, 42-47.

67. Radchenko, M.V.; Thornton, J.; Merrick, M. Control of AmtB-GlnK complex formation by intracellular levels of ATP, ADP, and 2-oxoglutarate. J. Biol. Chem. 2010, 285, 31037-31045.

68. Truan, D.; Huergo, L.F.; Chubatsu, L.S.; Merrick, M.; Li, X.D.; Winkler, F.K. A new P(II) protein structure identifies the 2-oxoglutarate binding site. J. Mol. Biol. 2010, 400, 531-539.

69. Kim, M.; Zhang, Z.; Okano, H.; Yan, D.; Groisman, A.; Hwa, T. Need-based activation of ammonium uptake in Escherichia coli. Mol. Syst. Biol. 2012, 8, 616.

70. Yuan, J.; Doucette, C.D.; Fowler, W.U.; Feng, X.-J.; Piazza, M.; Rabitz, H.A.; Wingreen, N.S.; Rabinowitz, J.D. Metabolomics-driven quantitative analysis of ammonia assimilation in E. coli. Mol. Syst. Biol. 2009, 5, 302.

71. Commichau, F.M.; Forchhammer, K.; Stulke, J. Regulatory links between carbon and nitrogen metabolism. Curr. Opin. Microbiol. 2006, 9, 167-172.

72. Mao, X.J.; Huo, Y.X.; Buck, M.; Kolb, A.; Wang, Y.P. Interplay between CRP-cAMP and PII-Ntr systems forms novel regulatory network between carbon metabolism and nitrogen assimilation in Escherichia coli. Nucleic Acids Res. 2007, 35, 1432-1440.

73. Jiang, P.; Ninfa, A.J. Escherichia coli PII signal transduction protein controlling nitrogen assimilation acts as a sensor of adenylate energy charge in vitro. Biochemistry 2007, 46, 12979-12996.

74. Ninfa, J.; Jiang, P. PII signal transduction proteins: Sensors of $\alpha$-ketoglutarate that regulate nitrogenmetabolism. Curr. Opin. Microbiol. 2005, 8, 168-173.

75. Hart, Y.; Madar, D.; Yuan, J.; Bren, A; Mayo, A.E.; Rabinowitz, J.D.; Alon, U. Robust control of nitrogen assimilation by a bifunctional enzyme in E. coli. Mol. Cell 2011, 41, 117-127.

76. Doucette, C.D.; Schwab, D.J.; Wingreen, N.S.; Rabinowitz, J.D. Alpha-ketoglutarate coordinates carbon and nitrogen utilization via enzyme I inhibition. Nat. Chem. Biol. 2011, 7, 894-901.

77. Powell, B.S.; Court, D.L.; Inada, T.; Nakamura, Y.; Michotey, V.; Cui, X.; Reizer, A.; Saier, M.H., Jr.; Reizer, J. Novel proteins of the phosphotransferase system encoded within the rpoN operon of Escherichia coli. Enzyme IIANtr affects growth on organic nitrogen and the conditional lethality of an erats mutant. J. Biol. Chem. 1995, 270, 4822-4839.

78. Peterkofski, A.; Wang, G.; Seok, Y.-J. Parallel PTS systems. Arch. Biochem. Biophys. 2006, 453, 101-107.

79. Pflüger-Grau, K.; Görke, B. Regulatory roles of the bacterial nitrogen-related phosphotransferase system. Trend Microbiol. 2010, 18, 205-214.

80. Lee, C.R.; Cho, S.H.; Yoon, M.J.; Peterkofsky, A.; Seok, Y.J. Escherichia coli enzyme IIANtr regulates the $\mathrm{K}^{+}$transporter TrkA. Proc. Natl. Acad. Sci. USA 2007, 104, 4124-4129. 
81. Lüttmann, D.; Heermann, R.; Zimmer, B.; Hillmann, A.; Rampp, I.S.; Jung, K.; Görke, B. Stimulation of the potassium sensor KdpD kinase activity by interaction with the phosphotransferase protein IIANtr in Escherichia coli. Mol. Micobiol. 2009, 72, 978-994.

82. Lee, C.-R.; Cho, S.-H.; Kim, H.-J.; Kim, M.; Peterkofsky, A.; Seok, Y.-J. Potassium mediates Escherichia coli enzyme IIANtr-dependent regulation of sigma factor selectivity. Mol. Microbiol. 2010, 78, 1468-1483.

83. Lüttmann, D.; Göpel, Y.; Görke, B. The phosphotransferase protein EIIANtr modulates the phosphate starvation response through interaction with histidine kinase PhoR in Escherichia coli. Mol. Microbiol. 2012, 86, 96-110.

84. Kim, H.-J.; Lee, C.-R.; Kim, M.; Peterkofsky, A.; Seok, Y.-J. Dephosphorylated NPr of the nitrogen PTS regulates lipid A biosynthesis by direct interaction with LpxD. Biochem. Biophys. Res. Commun. 2011,409, 556-561.

85. Lee, C.-R.; Park, Y.-H.; Kim, M.; Kim, Y.-R.; Park, S.; Peterkofsky, A.; Seok, Y.-J. Reciprocal regulation of the autophosphorylation of enzyme INtr by glutamine and $\alpha$-ketoglutarate in Escherichia coli. Mol. Microbiol. 2013, 88, 473-485.

86. Bykowski, T.; van der Ploeg, J.R.; Iwanicka-Nowicka, R.; Hryniewicz, M.M. The switch from inorganic to organic sulphur assimilation in Escherichia coli: Adenosine 5'-phosphosulphate (APS) as a signalling molecule for sulphate excess. Mol. Microbiol. 2002, 43, 1347-1358.

87. Kredich, N.M. Biosynthesis of Cysteine. In Escherichia coli and Salmonella: Cellular and Molecular Biology, 2nd ed.; Neidhardt, F.C., Curtiss, R., III, Ingraham, J.L., Lin, E.C.C., Low, K.B., Magasanik, B., Reznikoff, W.S., Riley, M., Schaechter, M., Umbarger, H.H., Eds.; ASM Press: Washington, DC, USA, 1996; Volume 1, pp. 514-527.

88. Iwanicka-Nowicka, R.; Hryniewicz, M.M. A new gene, $c b l$, encoding a member of the LysR family of transcriptional regulators belongs to Escherichia coli cys regulon. Gene 1995, 166, 11-17.

89. Zimmer, D.P.; Soupene, H.L.E.; Lee, V.F.; Wendisch, A.B.; Khodursky, B.J.; Peter, R.; Bender, A.; Kustu, S. Nitrogen regulatory protein Ccontrolled genes of Escherichia coli: Scavenging as a defense against nitrogen limitation. Proc. Natl. Acad. Sci. USA 2000, 97, 14674-14679.

90. Gyaneshwar, P.; Paliy, O.; McAuliffe, J.; Popham, D.L.; Jordan, M.I.; Kustu, S. Sulfur and nitrogen limitation in Escherichia coli K-12: Specific homeostatic responses. J. Bacteriol. 2005, 187, 1074-1090.

91. Wanner, B.L. Phosphorus Assimilation and Control of the Phosphate Regulon. In Escherichia Coli and Salmonella: Cellular and Molecular Biology; Neidhardt, F.C., Curtiss, R., III, Ingraham, J.L., Eds.; ASM Press: Washington, DC, USA, 1996; pp. 1357-1381.

92. Wanner, B.L. Gene regulation by phosphate in enteric bacteria. J. Cell. Biochem. 1993, 51, 47-54.

93. Baek, J.H.; Lee, S.Y. Transcriptome analysis of phosphate starvation response in Escherichia coli. J. Microbiol. Biotechnol. 2007, 17, 244-252.

94. Ruiz, N.; Silhavy, T.J. Constitutive activation of the Escherichia coli Pho regulon upregulates rpoS translation in an Hfq dependent fashion. J. Bacteriol. 2003,185, 5984-5992.

95. Taschner, N.P.; Yagil, E.; Spira, B. A differential effect of $\sigma s$ on the expression of the PHO regulon genes of Escherichia coli. Microbiology 2004, 150, 2985-2992.

96. Spira, B.; Silberstein, N.; Yagil, E. Guanosine 3',5'-bispyrophosphate (ppGpp) synthesis in cells of Escherichia coli starved for Pi. J. Bacteriol. 1995, 177, 4053-4058. 
97. Spira, B.; Yagil, E. The integration host factor (IHF) affects the expression of the phosphate-binding protein and of alkaline phosphatase in Escherichia coli. Curr. Microbiol. 1999, $38,80-85$.

98. Taschner, N.P.; Yagil, E.; Spira, B. The effect of IHF on $\sigma s$ selectivity of the phoA and pst promoters of Escherichia coli. Arch. Microbiol. 2006, 185, 234-237.

99. Schurdell, M.S.; Woodbury, G.M.; McCleary, W.R. Genetic evidence suggests that the intergenic region between $p s t A$ and $p s t B$ plays a role in the regulation of rpoS translation during phosphate limitation. J. Bacteriol. 2007, 189, 1150-1153.

100. Wanner, B.L.; Wilmes, M.R.; Young, D.C. Control of bacterial alkaline phosphatase synthesis and variation in an Escherichia coli K-12 phoR mutant by adenyl cyclase, the cyclic AMP receptor protein, and the phoM operon. J. Bacteriol. 1988, 170, 1092-1102.

101. Kang, Y.; Weber, K.D.; Qiu, Y.; Kiley, P.J.; Blattner, F.R. Genome-wide expression analysis indicates that FNR of Escherichia coli K-12 regulates a large number of genes of unknown function. J. Bacteriol. 2005, 187, 1135-1160.

102. Dann, C.E., III; Wakeman, C.A.; Sieling, C.L.; Baker, S.C.; Irnov, I.; Winker, W.C. Structure and mechanism of a metal-sensing regulatory RNA. Cell 2007, 130, 878-892.

103. Helmann, J.D. Measuring metals with RNA. Mol. Cell. 2007, 27, 859-860.

104. Zheng, M.; Doan, B.; Schneider, T.D.; Storz, G. OxyR and SoxRS regulation of fur. J. Biotechnol. 1999, 181, 4639-4643.

105. McHugh, J.P.; Rodríguez-Quiñones, F.; Abdul-Tehrani, H.; Svistunenko, D.A.; Poole, R.K.; Cooper, C.E.; Andrews, S.C. Global iron-dependent gene regulation in Escherichia coli. J. Biol. Chem. 2003, 278, 29478-29486.

106. Storz, G.; Imlay, J.A. Oxidative stress. Curr. Opin. Microbiol. 1999, 2, 188-194.

107. Gennis, R.B.; Stewart, V. Respiration in Escherichia coli and Salmonella: Cellular and Molecular Biology; Bock, A., Curtiss, R., III, Kaper, J.B., Neidhardt, F.C., Nystrom, T., Rudd, K.E., Squires, C.L., Eds.; ASM Press: Washington, DC, USA, 1996.

108. Jovanovic, G.; Lloyde, L.J.; Stumpf, M.P.; Mayhew, A.J.; Buck, M. Induction and function of the phase shock protein extracytoplasmic stress response in Escherichia coli. J. Biol. Chem. 2006, 281, 21147-21161.

109. Blanchard, J.R.; Wholey, W.Y.; Conlon, E.M.; Pomposiello, P.J. Rapid changes in gene expression dynamics in response to superoxide reveal SoxRS dependent and independent transcriptional network. PLoS One 2007, 2, e1186.

110. Brynildsen, M.P.; Liao, J.C. An integrated network approach indentifies the isobutanol response network of Escherichia coli. Mol. Syst. Biol. 2009, 5, 277.

111. Braun, V. Regulation of iron uptake minimizes iron-mediated oxidative stress. J. Biosci. 1998, 23, 483-489.

112. Azpiroz, M.F.; Lavińa, M. Involvement of enterobactin synthesis pathway in production of Microcin H47. Antimicrob. Agents Chemother. 2004, 48, 1235-1241.

113. Semsey, S.; Andersson, A.M.; Krishna, S.; Jensen, M.H.; Masse, E.; Sneppen, K. Genetic regulation of fluxes: Iron homeostasis of Escherichia coli. Nucleic Acids Res. 2006, 34, 4960-4967.

114. Hantash, F.M.; Ammerlaan, M.; Earhart, C.F. Enterobactin synthase polypeptides of Escherichia coli are present in an osmotic-shocksensitive cytoplasmic locality. Microbiology 1997, 143, 147-156. 
115. Kumar, R.; Shimizu, K. Transcriptional regulation of main metabolic pathways of cyoA, cydB, fnr, and fur gene knockout Escherichia coli in C-limited and N-limited aerobic continuous cultures. Microb. Cell Fact. 2011, 10, 3.

116. Zhang, Z.; Gosset, G.; Barabote, R.; Gonzalez, C.S.; Cuevas, W.A.; Saier, M.H., Jr. Functional interactions between the carbon and iron utilization regulators, Crp and Fur, in Escherichia coli. J. Bacteriol. 2005, 187, 980-990.

117. Ali Azam, T.; Iwata, A.; Nishimura, A.; Ueda, S.; Ishihama, A. Growth phase-dependent variation in protein composition of the Escherichia coli nucleoid. J. Bacteriol. 1999, 181, 6361-6370.

118. Bradley, M.D.; Beach, M.B.; de Koning, J.A.P.; Pratt, T.S.; Osuna, R. Effects of Fis on Escherichia coli gene expression during different growth stages. Microbiology 2007, 153, 2922-2940.

119. Mallik, P.; Pratt, T.S.; Beach, M.B.; Bradley, M.D.; Undamatla, J.; Osuna, R. Growth phase-dependent regulation and stringent control of fis are conserved processes in enteric bacteria and involve a single promoter (fis P) in Escherichia coli. J. Bacteriol. 2004, 186, $122-135$.

120. Mallik, P.; Paul, B.J.; Rutherford, S.T.; Gourse, R.L.; Osuna, R. DksA is required for growth phase-dependent regulation, growth rate-dependent control, and stringent control of fis expression in Escherichia coli. J. Bacteriol. 2006, 188, 5775-5782.

121. Paul, B.J.; Berkmen, M.B.; Gourse, R.L. DksA potentiates direct activation of amino acid promoters by ppGpp. Proc. Natl. Acad. Sci. USA 2005, 102, 7823-7828.

122. Ferenci, T. Hungry bacteria - definition and properties of a nutritional state. Environ. Microbiol. 2001, 3, 605-611.

123. Hardiman, T.; Lemuth, K.; Keller, M.A.; Reuss, M.; Siemann-Herzberg, M. Topology of the global regulatory network of carbon limitation in Escherichia coli. J. Biotechnol. 2007, 132, 359-374.

124. Braeken, K.; Moris, M.; Daniels, R.; Vanderleyden, J.; Michiels, J. New horizons for (p)ppGpp in bacterial and plant physiology. Trends Microbiol. 2006, 14, 45-54.

125. Artsimovitch, I.; Patlan, V.; Sekine, S.; Vassylyeva, M.N.; Hosaka, T.; Ochi, K.; Yokoyama, S. Structural basis for transcription regulation by alarmone ppGpp. Cell 2004, 117, 299-310.

126. Kanjee, U.; Ogata, K.; Houry, W.A. Direct binding targets of the stringent response alarmone(p)ppGpp. Mol. Micobiol. 2012, 85, 1029-1043.

127. Hengge-Aronis, R. Signal transduction and regulatory mechanisms involved in control of the $\sigma^{s}$ (RpoS) subunit of RNA polymerase. Microbiol. Mol. Biol. Rev. 2002, 66, 373-395.

128. Patten, C.L.; Kirchhof, M.G.; Schertzberg, M.R.; Morton, R.A.; Schellhorn, H.E. Microarray analysis of RpoS-mediated gene expression in Escherichia coli K-12. Mol. Genet. Genomics 2004, 272, 580-591.

129. Jishage, M.; Kvint, K.; Shingler, V.; Nystrom, T. Regulation of $\sigma$ factor competition by the alarmone ppGpp. Genes Dev. 2002, 16, 1260-1270.

130. Aronis, H.R. Regulation of Gene Expression during Entry into Stationary Phase. In Escherichia Coli and Salmonella: Cellular and Molecular Biology, 2nd ed.; Neidhardt, F.C., Curtiss, R., III, Ingram, J.L., Eds.; ASM Press: Washington, DC, USA, 1996; pp. 1497-1512. 
131. Aronis, H.R. Stationary phase gene regulation: What makes an Escherichia coli promoter $\sigma^{s}$-selective? Curr. Opin. Microbiol. 2002, 5, 591-595.

132. Lacour, S.; Landini, P. $\sigma^{s}$-dependent gene expression at the onset of stationary phase in Escherichia coli: Function of $\sigma^{s}$-dependent genes and identification of their promoter sequences. J. Bacteriol. 2004, 186, 7186-7195.

133. Vijayakumar, S.R.V.; Kirchhof, M.G.; Patten, C.L.; Schellhorn, H.E. RpoS-regulated genes of Escherichia coli identified by random lacZ fusion mutagenesis. J. Bacteriol. 2004, 186, 8499-8507.

134. Wei, B.; Shin, S.; LaPorte, D.; Wolfe, A.J.; Romeo, T. Global regulatory mutations in csrA and rpoS cause severe central carbon stress in Escherichia coli in the presence of acetate. J. Bacteriol. 2000, 182, 1632-1640.

135. Rahman, M.; Hasan, M.R.; Oba, T.; Shimizu, K. Effect of rpoS gene knockout on the metabolism of Escherichia coli during exponential growth phase and early stationary phase based on gene expressions, enzyme activities and intracellular metabolite concentrations. Biotech. Bioeng. 2006, 94, 585-595.

136. Weber, H.; Polen, T.; Heuveling, J.; Wendisch, V.F.; Hengge, R. Genome-wide analysis of the general stress response network in Escherichia coli: $\sigma^{s}$-Dependent genes, promoters, and sigma factor selectivity. J. Bacteriol. 2005, 187, 1591-1603.

137. Wang, X.; Dubey, A.K.; Suzuki, K.; Baker, C.S.; Babitzke, P.; Romeo, T. CsrA post-transcriptionally represses pgaABCD, responsible for synthesis of a biofilm polysaccharide adhesin of Escherichia coli. Mol. Microbiol. 2005, 56, 1648-1663.

138. Hengge, R. Principles of c-di-GMP signalling in bacteria. Nat. Rev. Microbiol. 2009, 7, 263-273.

139. Barnhart, M.M.; Chapman, M.R. Curli biogenesis and function. Annu. Rev. Microbiol. 2006, 60, $131-147$.

140. Thomason, M.K.; FFontaine, F.; de Lay, N.; Storz1, G. A small RNA that regulates motility and biofilm formation in response to changes in nutrient availability in Escherichia coli. Mol. Microbiol. 2012, 84, 17-35.

141. Dong, T.; Schellhorn, H.E. Control of RpoS in global gene expression of Escherichia coli in minimal media. Mol. Genet. Genomics 2009, 281, 19-33.

142. Jackson, D.W.; Simecka, J.W.; Romeo, T. Catabolite repression of Escherichia coli biofilm formation. J. Bacteriol. 2002, 184, 3406-3410.

143. Waters, C.M.; Bassler, B.L. Quorum sensing: Cell-to-cell communication in bacteria. Annu. Rev. Cell Dev. Biol. 2005, 21, 319-346.

144. Llorens, N.J.M.; Tormo, A.; Martínez-García, E. Stationary phase in gram-negative bacteria. FEMS Microbiol. Rev. 2010, 34, 476-495.

145. Desnues, B.; Cuny, C.; Gregori, G.; Dukan, S.; Aguilaniu, H.; Nyström, T. Differential oxidative damage and expression of stress defence regulons in culturable and non-culturable Escherichia coli cells. EMBO Rep. 2003, 4, 400-404.

146. Nagamitsu, H.; Murata, M.; Kosaka, T.; Kawaguchi, J.; Mori, H.; Yamada, M. Crucial roles of MicA and RybB as vital factors for $\sigma^{\mathrm{E}}$-dependent cell lysis in Escherichia coli long-term stationary phase. J. Mol. Microbiol. Biotechnol. 2013, 23, 227-232.

147. Murata, M.; Noor, R.; Nagamitsu, H.; Tanaka, S.; Yamada, M. Novel pathway directed by sigma E to cause cell lysis in Escherichia coli. Genes Cells 2012, 17, 234-247. 
148. Noor, R.; Murata, M.; Yamada, M. Oxidative stress as a trigger for growth phase-specific sigmaE-dependent cell lysis in Escherichia coli. J. Mol. Microbiol. Biotechnol. 2009, 17, 177-187.

149. Pomposiello, P.J.; Demple, B. Redox-operated genetic switches: The SoxR and OxyR transcription factors. Trends Biotechnol. 2001, 19, 109-114.

150. Gaudu, P.; Weiss, B. SoxR, a [2Fe-2S] transcription factor, is active only in its oxidized form. Proc. Natl. Acad. Sci. USA 1996, 93, 10094-10098.

151. Liochev, S.I.; Fridovich, I. The role of O2. -in the production of HO.: In vitro and in vivo. Free Radic. Biol. Med. 1994, 16, 29-33.

152. Greenberg, J.T.; Monach, P.; Chou, J.H.; Josephy, P.D.; Demple, B. Positive control of a global antioxidant defense regulon activated by superoxide-generating agents in Escherichia coli. Proc. Natl. Acad. Sci. USA 1990, 87, 6181-6185.

153. Kabir, M.M.; Shimizu, K. Investigation into the effect of $\operatorname{sox} R$ and $\operatorname{sox} S$ genes deletion on the central metabolism of Escherichia coli based on gene expressions and enzyme activities. Biochem. Eng. J. 2006, 30, 39-47.

154. Wolf, R.E.; Prather, D.M.; Shea, F.M. Growth-rate dependent alteration of 6-phosphogluconate dehydrogenase and glucose 6-phosphate dehydrogenase levels in Escherichia coli K-12. J. Bacteriol. 1979, 139, 1093-1096.

155. Tsaneva, I.R.; Weiss, B. soxR, a locus governing a superoxide response regulon in Escherichia coli K-12. J. Bacteriol. 1990, 172, 4197-4205.

156. Hanson, R.L.; Rose, C. Effects of an insertion mutation in a locus affecting pyridine nucleotide transhydrogenase (pnt::Tn5) on the growth of Escherichia coli. J. Bacteriol. 1980, 141, 401-404.

157. Mailloux, R.J.; Bériault, R.; Lemire, J.; Singh, R.; Chénier, R.R.; Hamel, R.D.; Appanna, V.D. The tricarboxylic acid cycle, an ancient metabolic network with a novel twist. PLoS One 2007, 2, e690.

158. Johnson, P. Antioxidant enzyme expression in health and disease: Effects of exercise and hypertension. Comp. Biochem. Physiol. C Toxicol. Pharmacol. 2002, 133, 493-505.

159. Foster, J.W. Escherichia coli acid resistance: Tales of an amateur acidophile. Nat. Rev. Microbiol. 2004, 2, 898-907.

160. Stincone, A.; Daudi, N.; Rahman, A.S.; Antczak, P.; Henderson, I.; Cole, J.; Johnson, M.D.; Lund, P.; Falciani, F. A systems biology approach sheds new light on Escherichia coli acid resistance. Nucleic Acids Res. 2011, 39, 7512-7528.

161. Richard, H.T.; Foster, J.W. Acid resistance in Escherichia coli. Adv. Appl. Microbiol. 2003, 52, 167-186.

162. Richard, H.T.; Foster, J.W. Escherichia coli glutamate- and arginine- dependent acid resistance systems increase internal $\mathrm{pH}$ and reverse transmembrane potential. J. Bacteriol. 2004, $86,6032-6041$.

163. Gong, S.; Richard, H.; Foster, J.W. YjdE (AdiC) is the arginine: Agmatine antiporter essential for arginine-dependent acid resistance in Escherichia coli. J. Bacteriol. 2003, 185, 4402-4409.

164. Iyer, R.; Williams, C.; Miller, C. Arginin-agmatine antiporter in extreme acid resistance in Escherichia coli. J. Bacteriol. 2003, 185, 6556-6561. 
165. Castanie-Cornet, M.P.; Foster, J.W. Escherichia coli acid resistance: cAMP receptor protein and a $20 \mathrm{bp}$ cis-acting sequence control $\mathrm{pH}$ and stationary phase expression of the gadA and gadBC glutamate decarboxylase genes. Microbiology 2001, 147, 709-715.

166. Martin-Galiano, A.J.; Ferrandiz, M.J.; de La Campa, A.G. The promoter of the operon encoding the F0F1 ATPase of Streptococcus pneumonia is inducible by pH. Mol. Microbiol. 2001, 41, 327-338.

167. Marzan, L.W.; Shimizu, K. Metabolic regulation of Escherichia coli and its phoB and phoR genes knockout mutants under phosphate and nitrogen limitations as well as at acidic condition. Microb. Cell Fact. 2011, 10, 39.

168. Suziedeliene, E.; Suziedelis, K.; Garbenciute, V.; Normark, S. The acid-inducible asr gene in Escherichia coli: Transcriptional control by the phoBR operon. J. Bacteriol. 1999, 181, 2084-2093.

169. Kitagawa, M.; Miyakawa, M.; Matsumura, Y.; Tsuchido, T. Escherichia coli small heat shock proteins, IbpA and IbpB, protect enzymes from inactivation by heat and oxidants. Eur. J. Biochem. 2002, 269, 2907-2917.

170. Sørensen, H.P.; Mortensen, K.K. Soluble expression of recombinant proteins in the cytoplasm of Escherichia coli. Microb. Cell Fact. 2005, 4, 1.

171. Hoffmann, F.; Weber, J.; Rinas, U. Metabolic adaptation of Escherichia coli during temperature-induced recombinant protein production: 1. Readjustment of metabolic enzyme synthesis. Biotechnol. Bioeng. 2002, 80, 313-319.

172. Tilly, K.; Erickson, J.; Sharma, S.; Georgopoulos, C. Heat shock regulatory gene rpoH mRNA level increases after heat shock in Escherichia coli. J. Bacteriol. 1986, 168, 1155-1158.

173. Tilly, K.; Spence, J.; Georgopoulos, C. Modulation of stability of the Escherichia coli heat shock regulatory factor $\sigma^{32}$. J. Bacteriol. 1989, 171, 1585-1589.

174. Shin, D.; Lim, S.; Seok, Y.J.; Ryu, S. Heat shock RNA polymerase $\left(\mathrm{E} \sigma^{32}\right)$ is involved in the transcription of $m l c$ and Crucial for Induction of the Mlc Regulon by Glucose in Escherichia coli. J. Biol. Chem. 2001, 276, 25871-25875.

175. Kumari, S.; Beatty, C.M.; Browning, D.F.; Busby, S.J.; Simel, E.J.; Hovel-Miner, G.; Wolfe, A.J. Regulation of acetyl coenzyme A synthetase in Escherichia coli. J. Bacteriol. 2000, 182, 4173-4179.

176. Browning, D.F.; Beatty, C.M.; Wolfe, A.J.; Cole, J.A.; Busby, S.J.W. Independent regulation of the divergent Escherichia coli $n r f A$ and acs $\mathrm{P} 1$ promoters by a nucleoprotein assembly at a shared regulatory region. Mol. Microbiol. 2002, 43, 687-701.

177. Beatty, C.M.; Browning, D.F.; Busby, S.J.W.; Wolfe, A.J. Cyclic AMP receptor protein-dependent activation of the Escherichia coliacsP2 promoter by a synergistic class III mechanism. J. Bacteriol. 2003, 185, 5148-5157.

178. Browning, D.F.; Beatty, C.M.; Sanstad, E.A.; Gunn, K.E.; Busby, S.J.W.; Wolfe, A.J. Modulation of CRP-dependent transcription at the Escherichia coliacsP2 promoter by nucleoprotein complexes: Anti-activation by the nucleoid proteins FIS and IHF. Mol. Microbiol. 2004, 51, 241-254.

179. Rahman, M.; Shimizu, K. Altered acetate metabolism and biomass production in several Escherichia coli mutants lacking rpoS-dependent metabolic pathway genes. Mol. Biosyst. 2008, $4,160-169$. 
180. Privalle, C.T.; Fridovich, I. Induction of superoxide dismutase in Escherichia coli by heat shock. Proc. Natl. Acad. Sci. USA 1987, 84, 2723-2726.

181. Dunlop, M.J. Engineering microbes for tolerance to next-generation biofuels. Biotechnol. Biofuels. 2011, 4, 32.

182. Isken, S.; de Bont, J.A.M. Bacteria tolerant to organic solvents. Extremophiles 1998, 2, 229-238.

183. Ramos, J.L.; Duque, E.; Gallegos, M.-T.; Godoy, P.; Ramos-Gonzalez, M.I.; Rojas, A.; Teran, W.; Segura, A. Mechanisms of solvent tolerance in Gram-negative bacteria. Annu. Rev. Microbiol. 2002, 56, 743-768.

184. Nicolaou, S.A.; Gaida, S.M.; Papoutsakis, E.T. A comparative view of metabolite and substrate stress and tolerance in microbial bioprocessing: From biofuels and chemicals, to biocatalysis and bioremediation. Metab. Eng. 2010, 12, 307-331.

185. Takatsuka, Y.; Chen, C.; Nikaido, H. Mechanism of recognition of compounds of diverse structures by the multidrug efflux pump AcrB of Escherichia coli. Proc. Natl. Acad. Sci. USA 2010, 107, 6559-6656.

186. Ankarloo, J.; Wikman, S.; Nicholls, I.A. Escherichia coli mar and acrAB mutants display no tolerance to simple alcohols. Int. J. Mol. Sci. 2010, 11, 1403-1412.

187. Piper, P. The heat-shock and ethanol stress responses of yeast exhibit extensive similarity and functional overlap. FEMS Microbiol. Lett. 1995, 134, 121-127.

188. Rutherford, B.J.; Dahl, R.H.; Price, R.E.; Szmidt, H.L.; Benke, P.I.; Mukhopadhyay, A.; Keasling, J.D. Functional genomic study of exogenous n-butanol stress in Escherichia coli. Appl. Environ. Microbiol. 2010, 76, 1935-1945.

189. Tomas, C.; Beamish, J.; Papoutsakis, E. Transcriptional analysis of butanol stress and tolerance in Clostridium acetobutylicum. J. Bacteriol. 2004, 186, 2006-2018.

190. Fiocco, D.; Capozzi, V.; Goffin, P.; Hols, P.; Spano, G. Improved adaptation to heat, cold, and solvent tolerance in Lactobacillus plantarum. Appl. Microbiol. Biotechnol. 2007, 77, 909-915.

191. Reyes, L.H.; Almario, M.P.; Kao, K.C. Genomic library screens for genes involved in n-butanol tolerance in Escherichia coli. PLoS One 2011, 6, e17678.

192. Sikkema, J.; de Bont, J.A.M.; Poolman, B. Mechanisms of membrane toxicity of hydrocarbons. Microbiol. Rev. 1995, 59, 201-222.

193. Holtwick, R.; Meinhardt, F.; Keweloh, H. Cis-trans isomerization of unsaturated fatty acids: Cloning and sequencing of the cti gene from Pseudomonas putida P8. Appl. Environ. Microb. 1997, 63, 4292-4297.

194. Kiran, M.; Prakash, J.; Annapoorni, S.; Dube, S.; Kusano, T.; Okuyama, H.; Murata, N.; Shivaji, S. Psychrophilic Pseudomonas syringae requires transmonounsaturated fatty acid for growth at higher temperature. Extremophiles 2004, 8, 401-410.

195. Wu, X.; Altman, R.; Eiteman, M.A.; Altman, E. Effect of overexpressing $n h a A$ and $n h a R$ on sodium tolerance and lactate production in Escherichia coli. J. Biol. Eng. 2013, 7, 3.

196. Minty, J.J.; Lesnefsky, A.A.; Lin, F.; Chen, Y.; Zaroff, T.A.; Velose, A.B.; Xie, B.; McConnell, C.A.; Ward, R.J.; Schwartz, D.R.; et al. Evolution combined with genomic study elucidates genetic bases of isobutanol tolerance in Escherichia coli. Microb. Cell Fact. 2011, 10, 18. 
197. Gutierrez-Rios, R.M.; Rosenblueth, D.A.; Loza, J.A.; Huerta, A.M.; Glasner, J.D.; Blattner, F.R.; Collado-Vides, J. Regulatory network of Escherichia coli: Consistency between literature knowledge and microarray profiles. Genome Res. 2003, 13, 2435-2443.

198. Maheswaran, M.; Forchhammer, K. Carbon-source-dependent nitrogen regulation in Escherichia coli is mediated through glutamine-dependent GlnB signaling. Microbiology 2003, 149, 2163-2172.

199. Quan, J.A.; Schneider, B.L.; Paulsen, I.T.; Yamada, M.; Kredich, N.M.; Saier, M.H., Jr. Regulation of carbon utilization by sulfur availability in Escherichia coli and Salmonella typhimurium. Microbiology 2002, 148, 123-131.

200. De Lorenzo, V.; Herrero, M.; Giovannini, F.; Neilands, J.B. Fur (ferric uptake regulation) protein and CAP (catabolite-activator protein) modulate transcription of fur gene in Escherichia coli. Eur. J. Biochem. 1998, 173, 537-546.

201. Dragosits, M.; Mozhayskiy, V.; Quinones-Soto, S.; Park, J.; Tagkopoulos, I. Evolutionary potential, cross-stress behavior and the genetic basis of acquired stress resistance in Escherichia coli. Mol. Syst. Biol. 2013, 9, 643.

202. Jenkins, D.; Schultz, J.; Matin, A. Starvation-induced cross protection against heat or $\mathrm{H}_{2} \mathrm{O}_{2}$ challenge in Escherichia coli. J. Bacteriol. 1988, 170, 3910-3914.

203. Jenkins, D.; Auger, E.; Matin, A. Role of RpoH, a heat shock regulator protein, in Escherichia coli carbon starvation protein synthesis and survival. J. Bacteriol. 1991, 173, 1992-1996.

204. Gunasekera, T.; Csonka, L.; Paliy, O. Genome-wide transcriptional responses of Escherichia coli K-12 to continuous osmotic and heat stresses. J. Bacteriol. 2008, 190, 3712-3720.

205. White-Ziegler, C.; Um, S.; Pérez, N.; Berns, A.; Malhowski, A.; Young, S. Low temperature (23 degrees C) increases expression of biofilm-, cold-shock- and RpoS-dependent genes in Escherichia coli K-12. Microbiology 2008, 154, 148-166.

206. Reaves, M.L.; Rabinowitz, J.D. Metabolomics in systems microbiology Review Article. Curr. Opin. Biotechnol. 2011, 22, 17-25.

(C) 2013 by the authors; licensee MDPI, Basel, Switzerland. This article is an open access article distributed under the terms and conditions of the Creative Commons Attribution license (http://creativecommons.org/licenses/by/3.0/). 